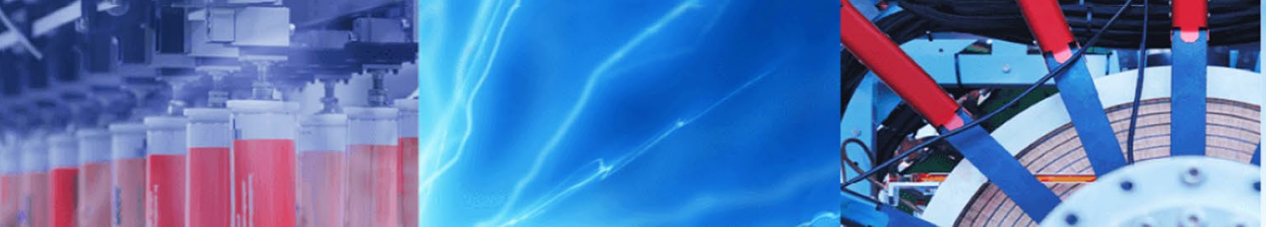

Research Article

\title{
Computer-aided design modeling of microstrip step discontinuity on multilayer iso/anisotropic substrates with transient signal analysis
}

\author{
Y. K. Awasthi ${ }^{1}$ (D) Himanshu Singh ${ }^{2} \cdot$ A. K. Verma ${ }^{2}$
}

(c) Springer Nature Switzerland AG 2019

\begin{abstract}
A computer-aided design modeling is presented to compute a shunt capacitance and series inductance of $\pi$ or T-equivalent network parameters of microstrip step-discontinuity at a junction on multilayer iso/anisotropic substrates. The results of the proposed model of shunt capacitance and series inductance have shown permissible agreement with simulation results by the average deviation of $4.5 \%$ and $4.9 \%$ for $1<\varepsilon_{r} \leq 40$ and $w_{1} / w_{2}<10$ respectively. Similarly, the transient signal propagation characteristics, such as arrival time of the pulse, rise-time, delay time, settling time, etc. are influenced by the anisotropy in the transmission line and said information's are also important for proper characterization of analog/ digital pulses on multilayer iso/anisotropic substrate planar transmission lines. The time-domain characteristic of transient pulses over microstrip stepped line with diverse conditions are strengthening the concept of interconnects, which plays a vital role in modern circuit technology. Proposed modeling concept is more accurate to design of contemporary planar microwave filters, impedance matching networks and VLSI interconnects.
\end{abstract}

Keywords Dispersion - Shunt capacitance - Series inductance SLR techniques · Very large scale integration (VLSI) . Pulses

\section{Introduction}

Several practical substrates as sapphire, boron nitride, PTFE and quartz have anisotropy and these substrates are largely used in MICs/MMICs circuit design. Anisotropy of the substrate has influenced the capacitance of a planar transmission line; consequently, the effective relative permittivity, characteristic impedance and other fostering parameters of the line will have to change [1]. Dissimilar step-width of the microstrip line is an important building block of Microwave Integrated Circuit (MIC) and Monolithic Microwave Integrated Circuit (MMIC) technology. The step-discontinuity occurs at the junction of two microstrip lines with different characteristic impedance. It is an essential element in the design of filters, matching networks, interconnects. So, its accurate description, including the effect of anisotropy in the substrate, is important for the computer-aided design of the conventional and monolithic MIC. The step discontinuity has been characterized through several means; such by the lumped equivalent circuit, equivalent section of microstrip lines and scattering parameters. Likewise, the transient signal propagation characteristics, such as arrival time of the pulse, rise-time, delay time, settling time, etc. are influenced by the anisotropy in the transmission line. Above considerations are important for proper characterization of analog/digital pulses on single/multilayer iso/anisotropic substrate planar transmission line [2]. Awasthi et al. have presented two $\mathrm{w} / \mathrm{h}$-dependent equivalent isotropic permittivity model of a microstrip line on the anisotropic substrate. Model one is valid to single layer anisotropic substrate; while the second model is formidable for microstrip multilayer anisotropy [3,

$\triangle$ Y. K. Awasthi, yash_ips79@rediffmail.com; Himanshu Singh,drhimanshusingh172@gmail.com; A. K. Verma, anandvrm48@gmail.com| ${ }^{1}$ Electronics and Communication Engineering, Manav Rachna International Institute of Research \& Studies, Faridabad, HR, India. ${ }^{2}$ Microwave Research Laboratory, Department of Electronic Science, University of Delhi, South Campus, New Delhi, India. 
4]. Single layer reduction (SLR) formulation is used to attain a w/h-dependent equivalent isotropy model and a dispersion model for microstrip line on an anisotropic substrate is also proposed $[5,6]$. The frequency characterization up to $12 \mathrm{GHz}$ is discussed through the lumped equivalent circuit and it is more helpful in the design process of MIC with microstrip step discontinuity $[7,8]$. High impedance transforming dual-band Balun with isolation and output ports matching is presented [9]. Design of compact dualband matching network with single unequal susceptance cancellation stub is illustrated [10].A novel concept of virtual impedance for high-frequency tri-band impedance matching networks and an enhanced frequency-ratio coupled-line dual-frequency Wilkinson power divider is also designed $[11,12]$.

In this article, CAD-based more accurate models of $C_{p}$ and $L_{s}$ are presented to analyze the step discontinuity at a junction on multilayer iso/anisotropic microstrip line. Furthermore, it is also explained the time-domain behavior of transient pulse on the microstrip transmission line, that is widely useful in VLSI-interconnects, planar microwave filter, and impedance matching networks. All results of the proposed models are compared with the EM-simulation results to prove the validity and ubiquity of models. The accuracy of proposed models is better than the existing ones.

\section{Analytical modeling of microstrip step discontinuity on Iso/anisotropic substrates}

First and foremost, in this section, a formulation of closed-form proposed model is summarized to compute the shunt capacitance and series inductance of the step discontinuity model as shown in Fig. 1, which is applicable only for the single layer isotropic substrate stepped microstrip line; whilst, the extension of the model to multilayer anisotropic substrate is also proposed. The

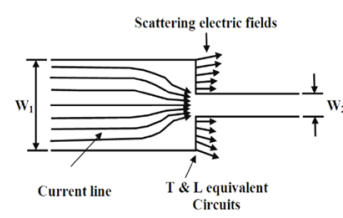

(a)

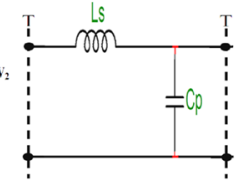

(b) (c)

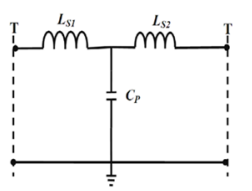

Fig. 1 Planar microstrip step discontinuity sample and equivalent circuit diagrams a current flow and scattered electric field at step, b $\mathrm{L} / \pi$ - type circuit and $\mathbf{c} \mathrm{T}$ - type circuit accuracy of models is verified against the results of the EM-simulation.

\subsection{Modeling for microstrip step discontinuity on single layer isotropic substrate}

The lossless microstrip step discontinuity is modeled as the T-network or alternately as the $L / \pi$-network as shown in Fig. 1b, c. Figure 1a shows the change in the strip width that causes variation in the characteristic impedance of the line. The junction of two dissimilar lines at the plane of discontinuity has reflection and the scattering of the electric field at the junction is produced a shunt capacitor $\mathrm{C}_{\mathrm{p}}$; while current crowding at the junction is developed a series inductance $L_{s}$. This description of the step discontinuity leads to the $L / \pi$-type circuit model as shown in Fig. 1b. Moreover, note that the junction is asymmetrical; therefore, some authors prefer to describe the step discontinuity by the asymmetrical T-network as shown in Fig. 1c [13]. A sum of the partial series inductance $L_{s 1}$ and $L_{s 2}$ is equal to the total series inductance $L_{s}$ of the $L / \pi-$ network. Improved closed-form models are presented to compute the shunt capacitor $C_{p}$ and the series inductance $L_{s}$. The shunt capacitor $\left(C_{p}\right)$ model is an improvised version which was suggested by Hoffmann [13]; whereas the series inductance $\left(L_{s}\right)$ is also an improvised version of the model suggested by Gupta et al. [1].

Improved Model for Shunt Capacitance $\left(C_{p}\right)$ The following equation is used to compute the shunt capacitance $C_{p}$ of isotropic microstrip step discontinuity on the microwave integrated circuits. Strip width of the microstrip line is $w_{1}$ and $w_{2}$ when $w_{1}>w_{2}$ :

$C_{p}=C_{f} \times\left(w_{1}-w_{2}\right)$

where $C_{f}$ is the fringe capacitance per unit length that is calculated by Eq. (2) and $w_{1}$ is the width of a wider line on substrate thickness $h$ with relative permittivity $\varepsilon_{\mathrm{r}}$.

$C_{f}=\frac{1}{2}\left[\frac{\varepsilon_{r, \text { eff } 1}}{Z_{0}\left(\varepsilon_{r}=1\right) \times c}-\frac{\varepsilon_{0} \varepsilon_{r} w_{1}}{h}\right]$

where $c\left(3 \times 10^{8} \mathrm{~m} / \mathrm{s}\right)$ is the velocity of the EM wave in free-space. The effective relative permittivity $\left(\varepsilon_{r, \text { eff } 1}\right)$ of the wider microstrip line and characteristics impedance onair substrate $Z_{0}\left(\varepsilon_{\mathrm{r}}=1\right)$ are obtained from the closed-form expressions of Hoffmann [13]. However, computed shunt capacitance $\left(C_{p}\right)$ of step by this method is incorrect and much deviated from the simulated results available from Sonnet [14] but the results given by model in Hoffmann [13] are improved by introducing the correction factor. The corrected model of shunt capacitance $C_{p \text { (corr) }}$ for step discontinuity is summarized below: 
$C_{p(\text { corr })}=\left[\frac{C_{p}}{\operatorname{IF}_{\left(\varepsilon_{r}\left(w_{1} / h\right),\left(w_{2} / h\right)\right)}}\right]$

The improvement factor $\left(\mathrm{IF}_{1\left(\varepsilon_{r}, \mathrm{w}_{1} / \mathrm{h}, \mathrm{w}_{2} / \mathrm{h}\right)}\right)$ is obtained through the multi-dimensional curve-fitted process. It is given below:

$\mathrm{IF}_{1\left(\varepsilon_{\mathrm{r}}, \mathrm{w}_{1} / \mathrm{h}, \mathrm{w}_{2} / \mathrm{h}\right)}=(10)^{\mathrm{y}} \quad$ (a) $\mathrm{y}=\mathrm{A}\left(\mathrm{w}_{1} / \mathrm{h}\right)^{\mathrm{B}}$

where parameters $A$ and $B$ are given by

$A=A_{1}\left(w_{2} / h\right)^{B_{1}} \quad$ (a) $B=A_{2}\left(w_{2} / h\right)^{B_{2}}$

where, parameters $A_{1}, B_{1}, A_{2}$, and $B_{2}$ are given by

$A_{1}=0.7785+0.0132 \varepsilon_{r} \quad$ (a)

$\mathrm{B}_{1}=0.4023+0.016 \varepsilon_{\mathrm{r}} \quad$ (b)

$A_{2}=0.632+0.02071 \varepsilon_{r} \quad$ (c)

$B_{2}=\left\{\begin{array}{l}0.2491+0.0077 \varepsilon_{r} \text { for } 2.3 \leq \varepsilon_{r}<9.6 \\ 0.49390 .01795 \varepsilon_{r} \text { for } 9.6 \leq \varepsilon_{r} \leq 15.1\end{array}\right.$

The proposed model has an average deviation within $4.5 \%$ against the results of EM-simulation (Sonnet) [14] for $1<\varepsilon_{\mathrm{r}} \leq 40$ and $\mathrm{w}_{1} / \mathrm{w}_{2}<10$. The improved model is adapted to the microstrip step discontinuity on the anisotropic substrate.

Improved Model for Series Inductance $\left(L_{s}\right)$ The series inductance $\left(L_{s}\right)$ is computed using improved version of Gupta et al. [1] model and this model are required S-parameters of the microstrip step discontinuity which is calculated by a circuit-simulation tool (Microwave Office) [15]. Circuit-simulation results are also compared against the S-parameters results of EM-simulation for the same microstrip step discontinuity. The original Gupta et al. [1] model is

$\frac{L_{s}}{h}=987 \times\left(1-\frac{Z_{02}}{Z_{01}} \sqrt{\frac{\varepsilon_{r, \text { eff } 2}}{\varepsilon_{r, \text { eff } 1}}}\right)^{2}$

where $Z_{01}$ and $Z_{02}$ are characteristic impedances of wider $\left(w_{1}\right)$ and narrow $\left(w_{2}\right)$ microstrip line respectively. The effective relative permittivity of the microstrip line $\left(w_{1}\right)$ and $\left(w_{2}\right)$ are $\varepsilon_{r, \text { eff } 1}$ and $\varepsilon_{r, \text { eff } 2}$ respectively. These line parameters are determined from the closed-form expressions of Hoffmann [13] and same can also be determined by using the Variational method as discussed in [3-6] but it is noted that the results obtained from both methods have a high error with respect to simulation results. Therefore improvement factor $\left(\mathrm{IF}_{2\left(\mathrm{w}_{1} / \mathrm{h}, \mathrm{w}_{2} / \mathrm{h}\right)}\right)$ is introduced to get the proposed model for the series inductance of step discontinuity. The corrected series inductance $L_{s \text { (corr) }}$ and its normalized form are obtained from
$\mathrm{L}_{\mathrm{s}(\text { corr })}=\mathrm{L}_{\mathrm{s}} \times \mathrm{IF}_{2\left(\mathrm{w}_{1} / \mathrm{h}, \mathrm{w}_{2} / \mathrm{h}\right)}$

$L_{n(\text { corr })}=\frac{L_{s(\text { corr })}}{L_{W_{2}} \times h}$

The expressions for the multiplicative improvement factor, $\mathrm{IF}_{2\left(\mathrm{w}_{1} / \mathrm{h}, \mathrm{w}_{2} / \mathrm{h}\right)}$ is obtained by the multidimensional curve-fitting.

$\mathrm{IF}_{2\left(\mathrm{w}_{1} / \mathrm{h}, \mathrm{w}_{2} / \mathrm{h}\right)}=\mathrm{Y}_{1\left(\mathrm{w}_{2} / \mathrm{h}\right)} \times\left(\frac{\mathrm{w}_{1}}{\mathrm{~h}}\right)^{-\mathrm{Y}_{2\left(\mathrm{w}_{2} / \mathrm{h}\right)}}$

The expressions for parameters $Y_{1}$ and $Y_{2}$ are summarized below:

For $0.5 \leq\left(\frac{\mathrm{w}_{1}}{\mathrm{~h}}\right)<3$ :

$Y_{1}=5.3063\left(\frac{W_{2}}{h}\right)^{3}-14.189\left(\frac{W_{2}}{h}\right)^{2}+17.43\left(\frac{W_{2}}{h}\right)-4.551$

For $3 \leq\left(\frac{\mathrm{w}_{1}}{\mathrm{~h}}\right) \leq 10$ :

$Y_{1}=-0.6556\left(\frac{w_{2}}{h}\right)^{6}+14.832\left(\frac{w_{2}}{h}\right)^{5}-107.14\left(\frac{w_{2}}{h}\right)^{4}$

$$
+341.36\left(\frac{w_{2}}{h}\right)^{3}-512.08\left(\frac{w_{2}}{h}\right)^{2}+350.29\left(\frac{w_{2}}{h}\right)-82.261
$$

For $\left(\frac{\mathrm{w}_{1}}{\mathrm{~h}}\right)>10$ :

$$
\begin{aligned}
Y_{1}= & -0.0485\left(\frac{w_{2}}{h}\right)^{6}+0.8205\left(\frac{w_{1}}{h}\right)^{5}-5.1389\left(\frac{w_{1}}{h}\right)^{4} \\
& +15.196\left(\frac{w_{1}}{h}\right)^{3}-22.259\left(\frac{w_{1}}{h}\right)^{2}+15.582\left(\frac{w_{1}}{h}\right)-2.7651
\end{aligned}
$$

The above-proposed model results have an average deviation within $4.9 \%$ against the results of EM-simulation (Sonnet) for $1<\varepsilon_{\mathrm{r}} \leq 40$ and $w_{1} / w_{2}<10$ [14].

\subsection{Modeling for step discontinuity on single layer anisotropic substrate}

The process of getting the equivalent single layer isotropic substrate corresponding to the anisotropic substrate microstrip line is explained. Two models have been presented for single layer anisotropic substrate and also note that the equivalent isotropic substrate is $\mathrm{w} / \mathrm{h}$ dependent. Therefore, the step discontinuity structure involving two microstrip lines of widths $w_{1}$ and $w_{2}$ provides two equivalent isotropic substrates [16-19]. It is needed only one equivalent isotropic substrate [3] in order to use the proposed model [Eq. (3)] for the shunt capacitance for single layer anisotropic substrate. But in this condition, w/hdependent equivalent isotropic relative permittivity, $\varepsilon_{\text {req,iso }}^{w_{1} / h}\left(w_{1} / h, \varepsilon_{r}^{*}\right)$ and $\varepsilon_{\text {req,iso }}^{w_{2} / h}\left(w_{2} / h, \varepsilon_{r}^{*}\right)$ corresponding to widths $w_{1}$ and $w_{2}$ of microstrips forming the step discontinuity is calculated and to obtain the intended w/hdependent equivalent common single substrate for the step discontinuity from the following expression, that is a 
geometric mean of both equivalent relative permittivities

$$
\begin{aligned}
& \varepsilon_{\text {req,iso }}^{\mathrm{w} / \mathrm{h}}\left(\mathrm{w}_{1} / \mathrm{h}, \mathrm{w}_{2} / \mathrm{h} \varepsilon_{\mathrm{r}}^{*}\right) \\
& =\sqrt{\varepsilon_{\text {req,iso }}^{\mathrm{w}_{1} / \mathrm{h}}\left(\mathrm{w}_{1} / \mathrm{h}, \varepsilon_{\mathrm{r}}^{*}\right) \times \varepsilon_{\text {req,iso }}^{\mathrm{w}_{2} / \mathrm{h}}\left(\mathrm{w}_{2} / \mathrm{h}, \varepsilon_{\mathrm{r}}^{*}\right)}
\end{aligned}
$$

However, the characteristic impedance $Z_{01}$ and $Z_{02}$ of the width $w_{1}$ and width $w_{2}$ on the original anisotropic substrate get modified for the step junction on the equivalent substrate with relative permittivity $\varepsilon_{\text {req,iso }}^{\mathrm{w} / \mathrm{h}}\left(\mathrm{w}_{1} / \mathrm{h}, \mathrm{w}_{2} / \mathrm{h}, \varepsilon_{\mathrm{r}}^{*}\right)$ and thickness $h$. In order to maintain the characteristic impedance of both lines on the equivalent substrate, to compute the modified widths, $\mathrm{w}_{1}^{\prime}$ and $\mathrm{w}_{2}^{\prime}$ on the equivalent substrate $\varepsilon_{\text {req,iso }}^{\mathrm{w} / \mathrm{h}}\left(\mathrm{w}_{1} / \mathrm{h}, \mathrm{w}_{2} / \mathrm{h}, \varepsilon_{\mathrm{r}}^{*}\right)$ corresponding to the original characteristic impedances $Z_{01}$ and $Z_{02}$. For the known original strip widths $w_{1}$ and $w_{2}$, the characteristic impedance $Z_{01}$ and $Z_{02}$ on the original substrate are computed using the $w / h$-dependent equivalent isotropic substrates $\varepsilon_{\text {req,iso }}^{\mathrm{w}_{1} / \mathrm{h}}\left(\mathrm{w}_{1} / \mathrm{h}, \varepsilon_{\mathrm{r}}^{*}\right)$ and $\varepsilon_{\text {req,iso }}^{\mathrm{w}_{2} / \mathrm{h}}\left(\mathrm{w}_{2} / \mathrm{h}, \varepsilon_{\mathrm{r}}^{*}\right)$. For this purpose, Hoffmann [13] closed-form expressions are used. The modified widths $\mathrm{w}_{1}^{\prime}$ and $\mathrm{w}_{2}^{\prime}$ on the equivalent isotropic substrate $\varepsilon_{\text {req,iso }}^{\mathrm{w} / \mathrm{h}}\left(\mathrm{w}_{1} / \mathrm{h}, \mathrm{w}_{2} / \mathrm{h}, \varepsilon_{\mathrm{r}}^{*}\right)$, corresponding to characteristic impedance $Z_{01}$ and $Z_{02}$, are obtained from the synthesis program [13]. At this stage, the proposed model from Eq. (3) is used to compute the shunt discontinuity capacitance $C_{p}$ for the step on the anisotropic substrate of the microstrip line. Where, permittivity $\left(\varepsilon_{\mathrm{r}}\right)$ is replaced by $\varepsilon_{\text {req,iso }}^{\mathrm{w} / \mathrm{h}}\left(\mathrm{w}_{1} / \mathrm{h}, \mathrm{w}_{2} / \mathrm{h}, \varepsilon_{\mathrm{r}}^{*}\right)$ and strip widths $\mathrm{w}_{1}$ and $\mathrm{w}_{2}$ are also replaced by the modified strip widths $w_{1}^{\prime}$ and $w_{2}^{\prime}$. All equivalent results of the single layer anisotropic substrate microstrip step against EM-Simulation results are discussed in sections (3).

\subsection{Model for microstrip step discontinuity on multilayer anisotropic substrate}

In addition to account the step discontinuity formed by two different widths of microstrip lines on the multilayer anisotropic substrates, the single layer reduction (SLR) process, discussed in [18], is used to get two equivalent substrates with relative permittivity $\varepsilon_{\text {req1,iso }}^{\mathrm{w} / \mathrm{H}}\left(\mathrm{w}_{1} / \mathrm{H}, \varepsilon_{\mathrm{ri}}^{*}\right)$ and $\varepsilon_{\text {req2,iso }}^{\mathrm{w} / \mathrm{H}}\left(\mathrm{w}_{2} / \mathrm{H}, \varepsilon_{\mathrm{ri}}^{*}\right)$ corresponding to two microstrip widths $w_{1}$ and $w_{2}$. Where, $i=1,2,3 \ldots$ so on represents the number of dielectric layers. Finally, we get an equivalent single substrate of the isotropic relative permittivity $\varepsilon_{\text {req,iso }}^{\mathrm{W} / \mathrm{H}}\left(\mathrm{W}_{1} / \mathrm{H}, \mathrm{W}_{2} / \mathrm{H}, \varepsilon_{\mathrm{ri}}^{*}\right)$ and thickness of multilayer substrates $\mathrm{H}$ is a summation of total layer thickness between upper and ground conductor. Hence, the isotropic equivalent relative permittivity for single layer single substrate is obtained by rewriting Eq. (11) for the multilayer boundary condition

$\varepsilon_{\text {req,iso }}^{\mathrm{w} / \mathrm{H}}\left(\mathrm{w}_{1} / \mathrm{H}, \mathrm{w}_{2} / \mathrm{H}, \varepsilon_{\mathrm{ri}}^{*}\right)$
$=\sqrt{\varepsilon_{\mathrm{req} 1, \text { iso }}^{\mathrm{w} / \mathrm{H}}\left(\mathrm{w}_{1} / \mathrm{H}, \varepsilon_{\mathrm{ri}}^{*}\right) \times \varepsilon_{\mathrm{req}, \text { iso }}^{\mathrm{w} / \mathrm{H}}\left(\mathrm{w}_{2} / \mathrm{h}, \varepsilon_{\mathrm{r}}^{*}\right)}$

Again, it is noted that for the known microstrip widths $w_{1}$ and $w_{2}$, the characteristic impedance $Z_{01}$ and $Z_{02}$ on the original multilayer anisotropic substrate have to be modified in order to maintain value of both the characteristic impedances on the single equivalent substrate with relative permittivity $\varepsilon_{\text {req,iso }}^{\mathrm{w} / \mathrm{H}}\left(\mathrm{w}_{1} / \mathrm{H}, \mathrm{w}_{2} / \mathrm{H}, \varepsilon_{\mathrm{ri}}^{*}\right)$ and substrate thickness $H$. The characteristic impedance $Z_{01}$ and $Z_{02}$ of two microstrip line corresponding to the strip widths $w_{1}$ and $w_{2}$ are computed using the $w / h$-dependent equivalent isotropic substrates [4] $\varepsilon_{\text {req1,iso }}^{\mathrm{w} / \mathrm{H}}\left(\mathrm{w}_{1} / \mathrm{H}, \varepsilon_{\mathrm{ri}}^{*}\right)$ and $\varepsilon_{\text {req2,iso }}^{\mathrm{w} / \mathrm{H}}\left(\mathrm{w}_{2} / \mathrm{H}, \varepsilon_{\mathrm{r}}^{*}\right)$. The modified widths $\mathrm{w}_{1}^{\prime}$ and $\mathrm{w}_{2}^{\prime}$ on the equivalent isotropic substrate $\varepsilon_{\text {req,iso }}^{w / h}\left(w_{1} / h, w_{2} / h, \varepsilon_{r}^{*}\right)$ are obtained from the synthesis program in which relative permittivity $\varepsilon_{\text {req,iso }}^{\mathrm{w} / \mathrm{H}}\left(\mathrm{w}_{1} / \mathrm{H}, \mathrm{w}_{2} / \mathrm{H}, \varepsilon_{\mathrm{ri}}^{*}\right)$ obtained from Eq. (12) and substrate thickness $\mathrm{H}$ is used. Moreover, in Eq. (3) permittivity $\left(\varepsilon_{\mathrm{r}}\right)$ is replaced by $\varepsilon_{\mathrm{req}, \mathrm{iso}}^{\mathrm{w} / \mathrm{H}}\left(\mathrm{w}_{1} / \mathrm{H}, \mathrm{w}_{2} / \mathrm{H}, \varepsilon_{\mathrm{ri}}^{*}\right)$ and the strip widths $w_{1}$ and $w_{2}$ also replaced by the modified strip widths $w_{1}^{\prime}$ and $w_{2}^{\prime}$ to compute the shunt capacitance (Cp) of the microstrip step-discontinuity model for multilayer anisotropic substrates. All equivalent results of the single layer anisotropic substrate microstrip step against EMSimulation results are discussed in sections (3).

\section{Frequency independent result analysis of proposed models}

In this section, to verify the accuracy of the proposed models of shunt capacitance $C_{p}$ for the microstrip step discontinuity on the single/multi-layer anisotropic substrate is illustrated and the reference data is extracted from the 3D-EM simulation (HFSS) tool, working on finite element method.

\subsection{Microstrip step discontinuity on single layer anisotropic substrate}

Initially, consider the case for $\mathrm{w}_{1}>\mathrm{w}_{2}$ on the sapphire having permittivity $\varepsilon_{\mathrm{rxx}}=9.4, \varepsilon_{\mathrm{ryy}}=11.60$ and substrate thickness $\mathrm{h}=0.638 \mathrm{~mm}$. However, further equally consider the case for $w_{2}>w_{1}$ but for the case when $w_{2}>w_{1}$, the above-discussed models for the shunt capacitance $C_{p}$, the role of $w_{1}$ and $w_{2}$ is interchanged. Figure $2 a, b$ shows the 

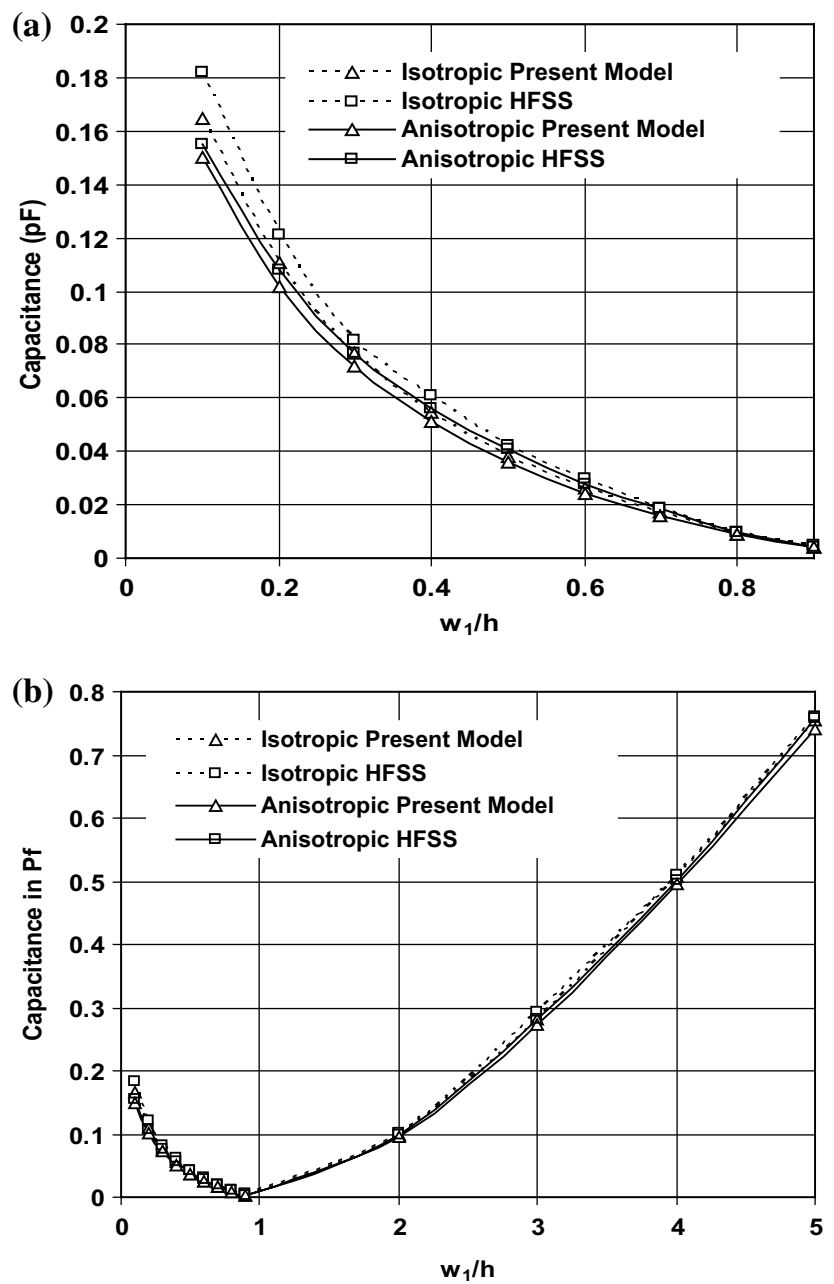

(c)

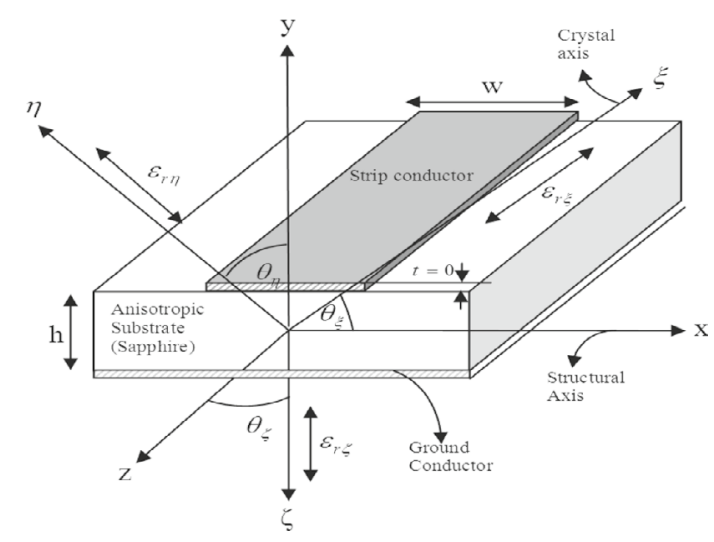

Fig. 2 Shunt capacitance $\left(C_{p}\right)$ for microstrip step discontinuity on single layer anisotropic substrate (sapphire), $w_{2} / h=1.0$, $\mathrm{h}=0.638 \mathrm{~mm}$ a $0.1 \leq \mathrm{w}_{1} / \mathrm{h}<1.0$, b $0.1 \leq \mathrm{w}_{1} / \mathrm{h} \leq 5.0$. c General presentation of anisotropy with arbitrary orientation of crystal direction

variation of the $C_{p}$ on both the isotropic and anisotropic substrate with $\mathrm{w}_{1} / \mathrm{h}$ ratio. It is calculated by the Eq. (3) with proper substrate conditions as discussed in sections

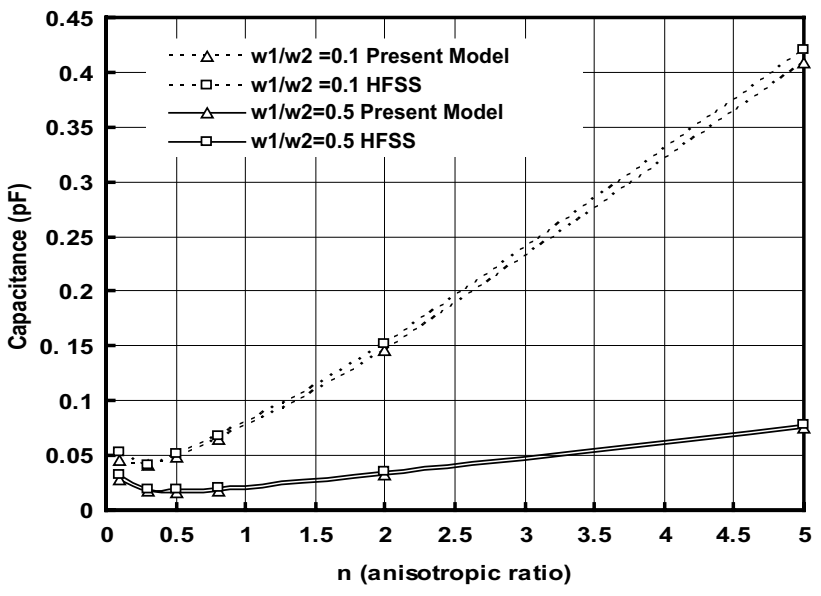

Fig. 3 Variation of $\left(C_{p}\right)$ with respect to the anisotropic ratio $(n)$ for microstrip step discontinuity on single layer anisotropic (i.e. sapphire) at $\mathrm{w}_{1} / \mathrm{w}_{2}<1$

(2). For isotropic substrate, both components of the relative permittivity are identical i.e. $\varepsilon_{\mathrm{rxx}}=11.60, \varepsilon_{\mathrm{ryy}}=11.60$ and $\mathrm{h}=0.638 \mathrm{~mm}$. Thus, noted that the $\mathrm{xx}$-component of permittivity of the anisotropic substrate is less than the isotropic substrate.

The fringe capacitance of the step discontinuity is increased with increase in the value of $\varepsilon_{\mathrm{rxx}}$-component of the relative permittivity. Figure $2 a, b$ shows that the shunt capacitance $C_{p}$ is more for the isotropic substrate as compared to the anisotropic substrate.

The $w_{2} / h=1.0$ is fixed, therefore $w_{1} / h=0.1$ form a large step discontinuity giving a high value of the shunt capacitance $C_{p}$. On increasing the value $w_{1} / h$ from 0.1 to 1.0 , decreases the value of the shunt capacitance $C_{p}$ as shown in Fig. $2 \mathrm{a}$ and it is also shown that the proposed model follows closely the extracted results of the shunt capacitance $\left(C_{p}\right)$ by EM-simulation.

Figure $2 b$ show the variation of the $C_{p}$ for both isotropic and anisotropic substrates when $w_{2}>w_{1}$. In addition, when $w_{1}>w_{2}$, the shunt capacitance $C_{p}$ increases once $\mathrm{w}_{1} / \mathrm{h}$ in increased from 1.0 to 5.0 . Further, the shunt capacitance $C_{p}$ of the isotropic substrate is more than that of the anisotropic substrate. The proposed model follows the results of HFSS closely. The average deviation is of the model is 3\% against the results of the HFSS for the anisotropic substrate and for the range $0.1 \leq w_{1} / w_{2} \leq 5, w_{2} / h=1.0$ and this is less than the deviation in the model for the isotopic substrate proposed by Hoffmann's model [13]. In some conditions, the anisotropic ratio $n=\sqrt{\varepsilon_{\text {rxx }} / \varepsilon_{\text {ryy }}}$ could be much higher than that of the sapphire substrate. Figure 3 is considered the variation of the shunt capacitance $\left(C_{p}\right)$ with respect to the anisotropic ratio $(n)$. Figure 3 
is also illustrated the condition, when $w_{1}<w_{2}$ i.e. for $w_{1} /$ $w_{2}=0.1,0.5$. For the isotropic substrate; $n=1.0$ and for anisotropy; $\mathrm{n}>1.0$ the $x \mathrm{x}$-component of the anisotropic relative permittivity is more than that of the isotropic relative permittivity. This is confirmed by the monotonic increase in the shunt capacitance $C_{p}$ with respect to the anisotropic ratio $(n)$. For the case $n<1$, the shunt capacitance $C_{p}$ decreases as compared to the $C_{p}$ when $n=1.0$. The yycomponent of the relative permittivity is throughout constant with $\varepsilon_{\text {ryy }}=11.6$. Figure 3 shows that the proposed model follows the results of HFSS even for the arbitrarily large anisotropic ratio (n).

\subsection{Microstrip step discontinuity on multi-layer anisotropic substrate}

In this section, two important cases of anisotropic multilayer microstrip lines i.e. composite and suspended are discussed. The composite substrate microstrip structure is valuable in the MMIC technology due to its compactness and the suspended microstrip structure is accommodating low-loss, low dispersion, and high characteristic impedance. In modern technologies, both structures are extensively used to design circuits and components by involving the step discontinuity. Therefore, the shunt capacitance $C_{p}$ at step discontinuity on both structures is tested and the accuracy of the proposed model against the results extracted from EM-simulation is rational.

Microstrip Step Structure on Composite Substrate A microstrip step discontinuity on the anisotropic composite substrate i.e. barium nitrate $\left(\varepsilon_{\mathrm{r} 2 \mathrm{xx}}=3.4, \varepsilon_{\mathrm{r} 2 \mathrm{yy}}=5.12\right.$, $\left.\mathrm{h}_{2}=0.038 \mathrm{~mm}\right)$ and alumina $\left(\varepsilon_{\mathrm{r} 1 \mathrm{xx}}=8.607, \varepsilon_{\mathrm{r} 1 \mathrm{yy}}=10.159\right.$,

(a)

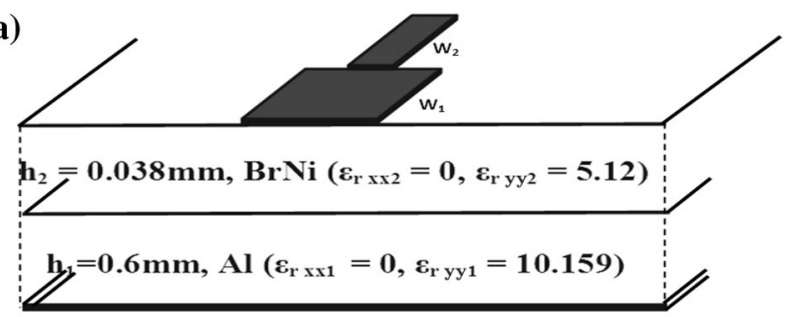

(b)

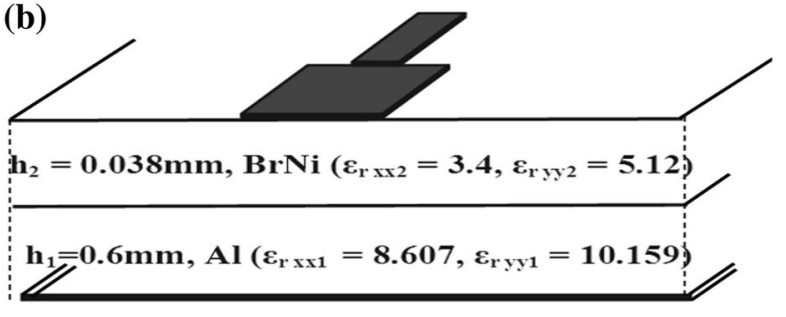

Fig. 4 Step discontinuity on anisotropic composite layer substrate a Anisotropy of substrate is ignored, b anisotropy of substrate is included
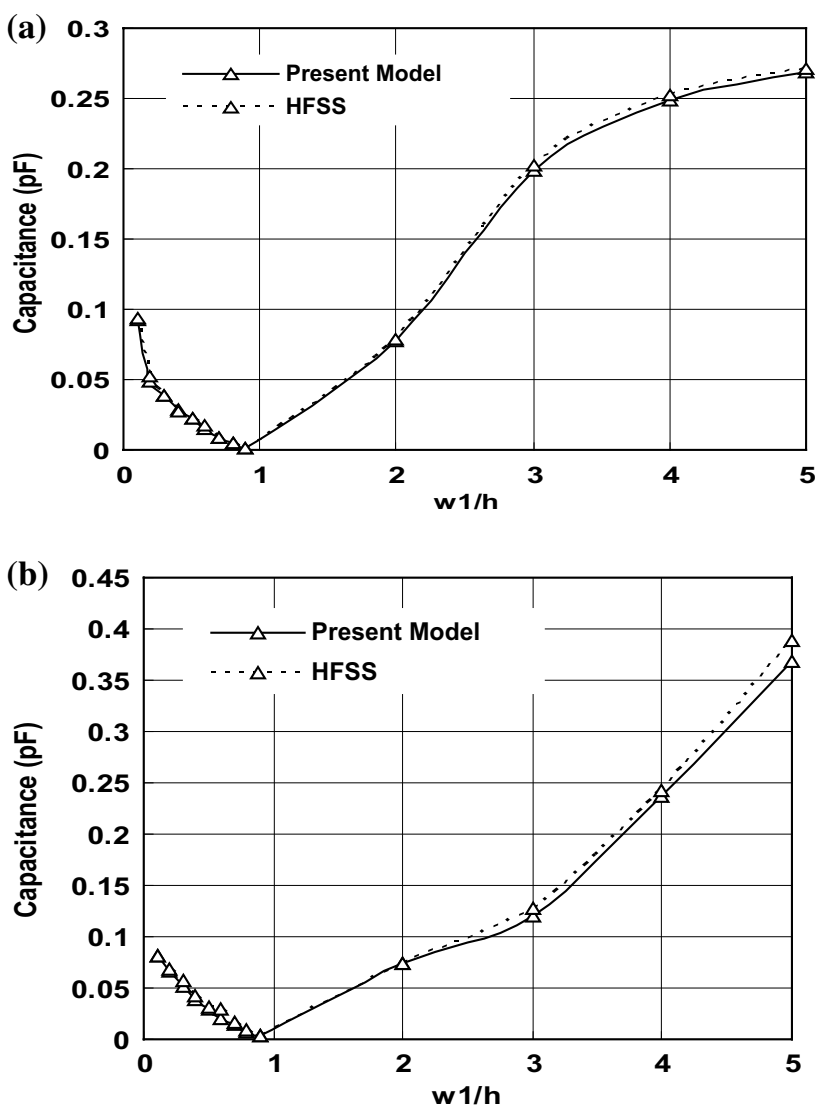

Fig. 5 Capacitance $\left(C_{p}\right)$ of the microstrip step discontinuity for a $\varepsilon_{\mathrm{r} \mathrm{xx}}=0.0, \mathrm{w}_{2} / \mathrm{H}=1.0, \mathrm{H}=\mathrm{h}_{1}+\mathrm{h}_{2}=0.638 \mathrm{~mm}$, b barium nitrate $\left(\varepsilon_{\mathrm{r} 2 \mathrm{xx}}=3.4, \varepsilon_{\mathrm{r} 2 \mathrm{yy}}=5.12\right)$, alumina $\left(\varepsilon_{\mathrm{r} 1 \mathrm{xx}}=8.607, \varepsilon_{\mathrm{r} 1} \mathrm{yy}=10.159\right)$, $\mathrm{W}_{2} / \mathrm{h}=1.0, \mathrm{H}=0.638 \mathrm{~mm}$

$\mathrm{h}_{1}=0.6 \mathrm{~mm}$ ) is shown in Fig. 4 . In order to analysis the model for isotropic substrate, Fig. 4a ignores the anisotropy in both the layers with $\mathrm{w}_{2} / \mathrm{h}=1.0, \mathrm{H}=\mathrm{h}_{1}+\mathrm{h}_{2}=0.638 \mathrm{~mm}$ and the ratio value $\left(w_{1} / h\right)$ is changed from 0.1 to 5 . Figure 5 a shows good agreement between the results computed by the proposed model and the results extracted from the HFSS has average deviation 3.2\%. It is also noted that the boron nitride on alumina as per Fig. $4 \mathrm{~b}$ shows the average deviation $6.5 \%$ as results shown in Fig. $5 \mathrm{~b}$.

Figure $6 a, b$ shows the results of $C_{p}$ with respect to the anisotropic ratio (n) for microstrip step discontinuity on multilayer anisotropic substrate for $w_{1} / w_{2}<1$ and $w_{1} /$ $\mathrm{W}_{2}>1.0$ respectively. The present model follows the results of HFSS and it is just like the single layer substrate condition and Fig. $5 \mathrm{a}$, $\mathrm{b}$ shows good agreement between the results computed by the proposed model and the results extracted from the HFSS has average deviation $3.2 \%$ and $1.6 \%$ respectively.

Microstrip Step Structure on Suspended Substrate The microstrip step discontinuity on a suspended thin sapphire substrate $\varepsilon_{\mathrm{r} x \mathrm{x}}=9.4, \varepsilon_{\mathrm{ryy}}=11.60, \mathrm{~h}=0.038 \mathrm{~mm}$ with 

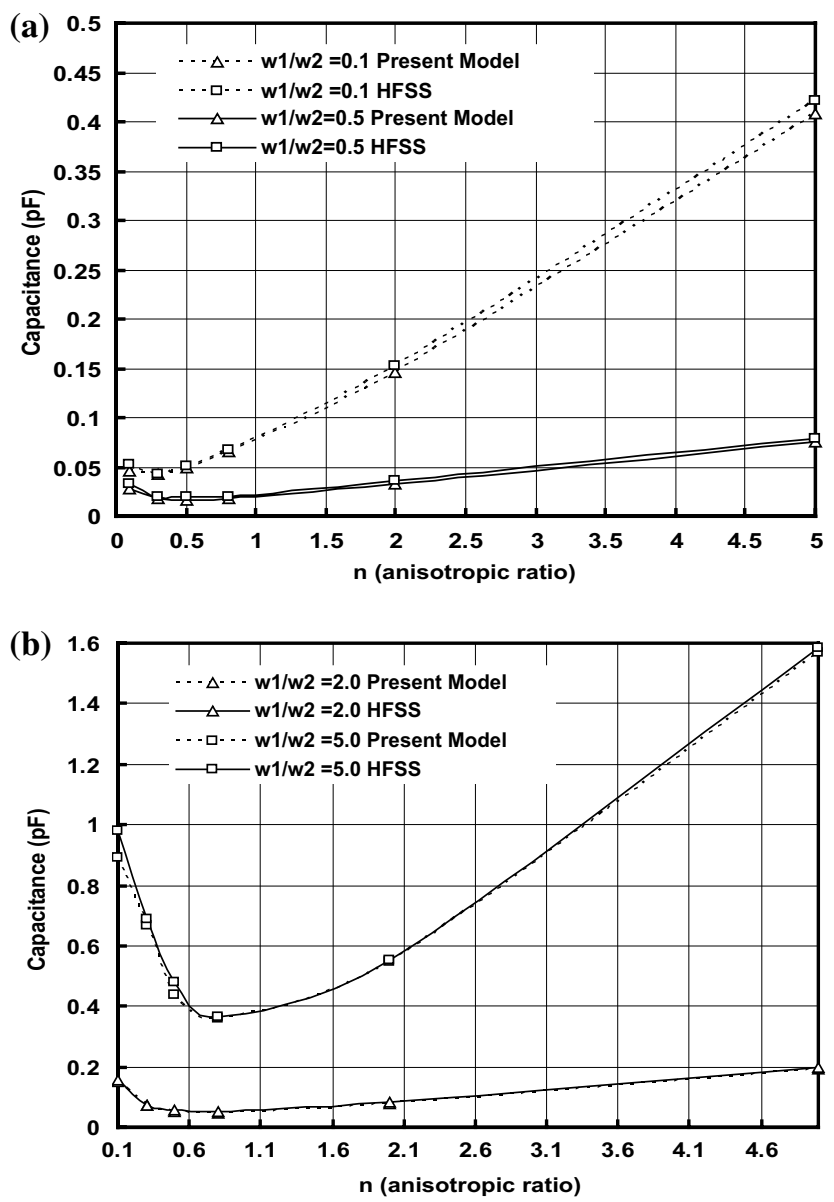

Fig. 6 Variation in $C_{p}$ for multilayer anisotropic step discontinuity for $\mathbf{a} w_{1} / w_{2}<1.0, \mathbf{b} w_{1} / w_{2}>1.0$ with respect to anisotropic ratio (n)

$0.6 \mathrm{~mm}$ thick layer of air-gap is shown in Fig. 7a. Figure $7 \mathrm{~b}$ represents the shunt capacitance of the step discontinuity on the suspended microstrip against the results of the HFSS. Both results follow each other closely. The shunt capacitance of the step discontinuity on the suspended substrate has an average error of 3.19\% against the results of the HFSS. Finally, to check the accuracy of the present model of the microstrip step discontinuity on the single and multilayer anisotropic substrate is verified on the circuit simulator (Microwave office) also [15]. The series inductance $\left(L_{s}\right)$ has also been discussed. The improved Gupta's model requires computation of characteristic impedances of both microstrip line on a single layer and multilayer anisotropic substrate [18]. Equivalent circuit model of step discontinuity is constructed on microwave circuit simulator like Microwave Office and S-parameters response of the equivalent circuit is extracted. Both the
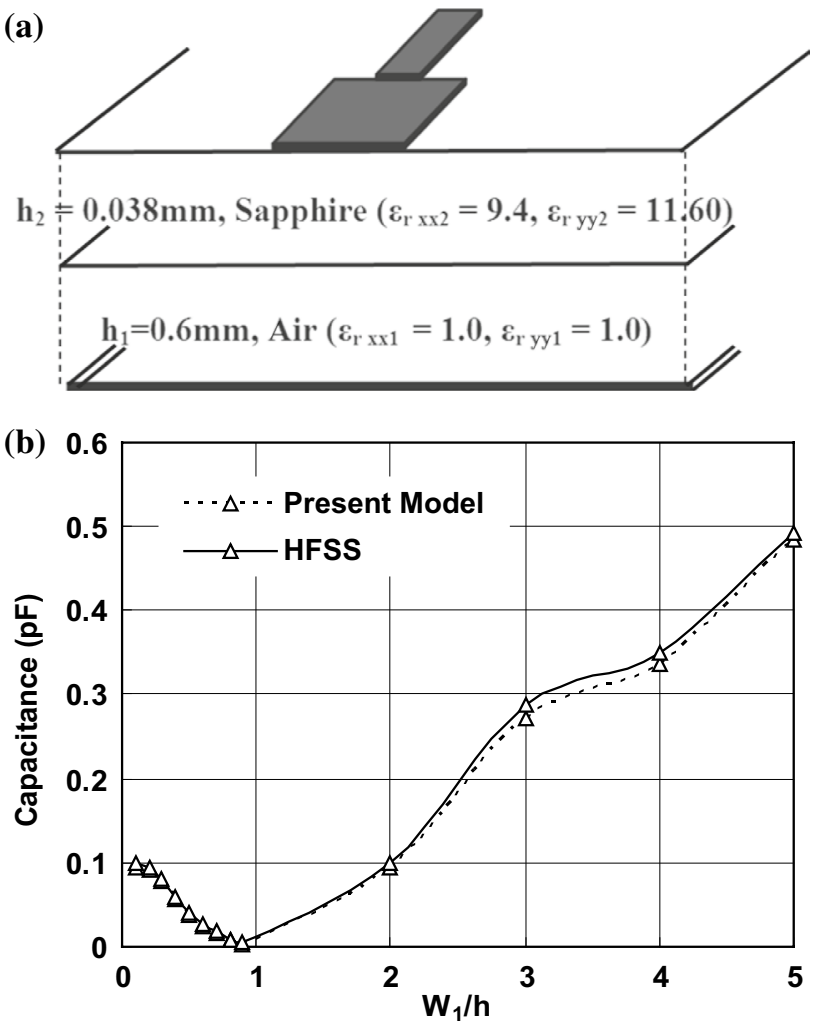

Fig. 7 a Sketch of microstrip step discontinuity on anisotropic suspended layer substrate, $\mathbf{b} C_{p}$ of the microstrip step discontinuity for sapphire suspended substrate with respect to $\mathrm{w}_{1} / \mathrm{h}$

S-parameter (extracted from EM and circuit simulation) responses are compared to ascertain the accuracy of the model for the shunt capacitance $C_{p}$.

\section{Frequency-dependent result analysis of proposed models}

Figure $8 \mathrm{a}$, b compare the S-parameters, as computed by the present circuit model against the results the HFSS of microstrip step discontinuity on the single layer sapphire (anisotropic) substrate and $\mathrm{w}_{2} / \mathrm{h}=1.0$ is fixed in the simulation process, while $w_{1} / h$ is taken as $0.1,3.0$. The simulation is done up to $20 \mathrm{GHz}$ but in next section for transient analysis, this proposed model is used up to $\mathrm{THz}$ frequency range. The nature of S-parameters response of the proposed model and HFSS are almost identical even though the circuit elements do not account for the frequency dependence.

In Fig. 9a, b compares the S-parameters of equivalent circuit model of the microstrip step-discontinuity 

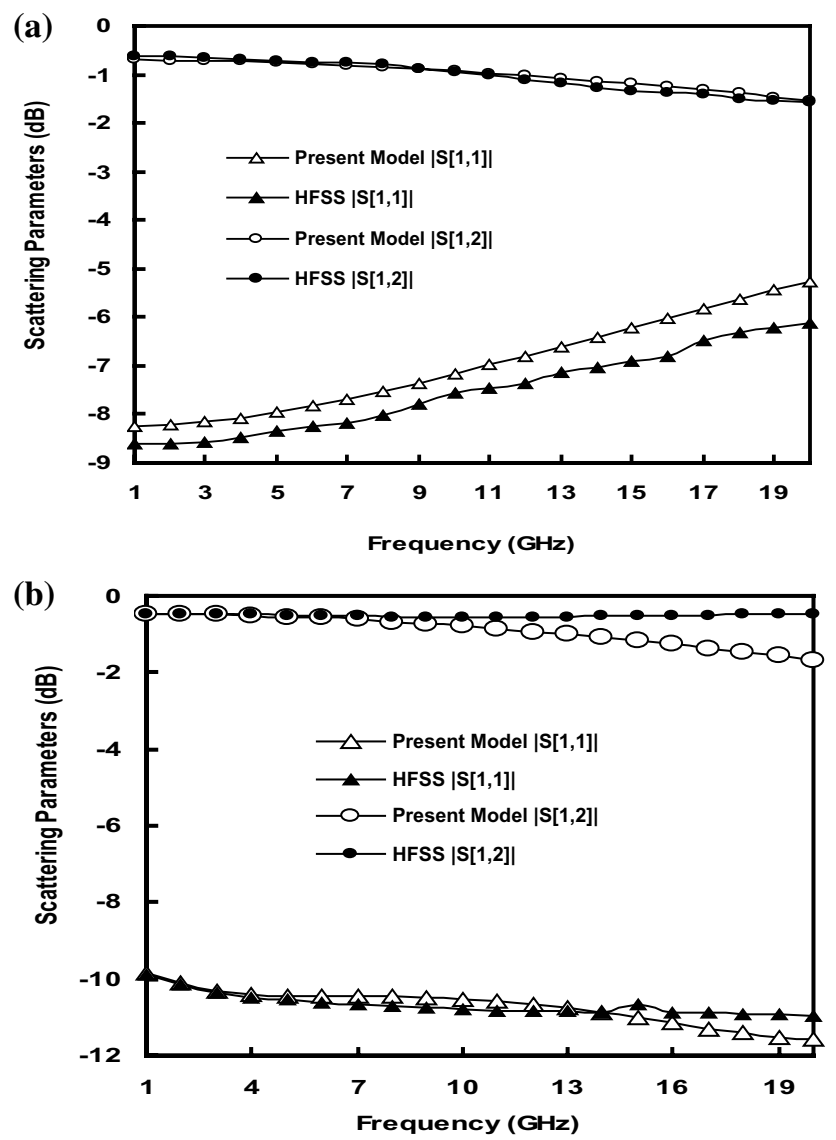

Fig. 8 Scattering parameters of microstrip step single layer anisotropic substrate at a $w_{1} / h=0.1, w_{2} / h=1.0, h=0.638 \mathrm{~mm}, \quad b$ $\mathrm{w}_{1} / \mathrm{h}=3.0, \mathrm{w}_{2} / \mathrm{h}=1.0, \mathrm{~h}=0.638 \mathrm{~mm}$

on multilayer anisotropic [Barium Nitrate and Alumina $\left.\left(\varepsilon_{\mathrm{r} 1 \mathrm{xx}}=\varepsilon_{\mathrm{r} 2 \mathrm{xx}}=0.0\right)\right]$ structure is shown with constant $\mathrm{w}_{2} / \mathrm{H}=1.0$ and $\mathrm{H}=\mathrm{h}_{1}+\mathrm{h}_{2}=0.638 \mathrm{~mm}$. For both cases $\left(w_{1} / H=0.3,2.0\right)$, responses from the circuit models are almost identical. Result shows some deviation up to $4.5 \%$ in $C_{p}$ and series inductance $\left(L_{s}\right)$ does have noticeable effect on the S-parameters responses as represented in Fig. 10a, b.

\section{Transient signal analysis of microstrip line on anisotropic substrate}

The distortion in the electrical pulses traveling on the planer transmission line occurs prominently due to the dispersive nature of the line. The losses increase the attenuation for signal and associated overshoot, undershoot, ringing, rise-time, etc. The distortion analysis of a pulse on the microstrip line is carried out normally for the
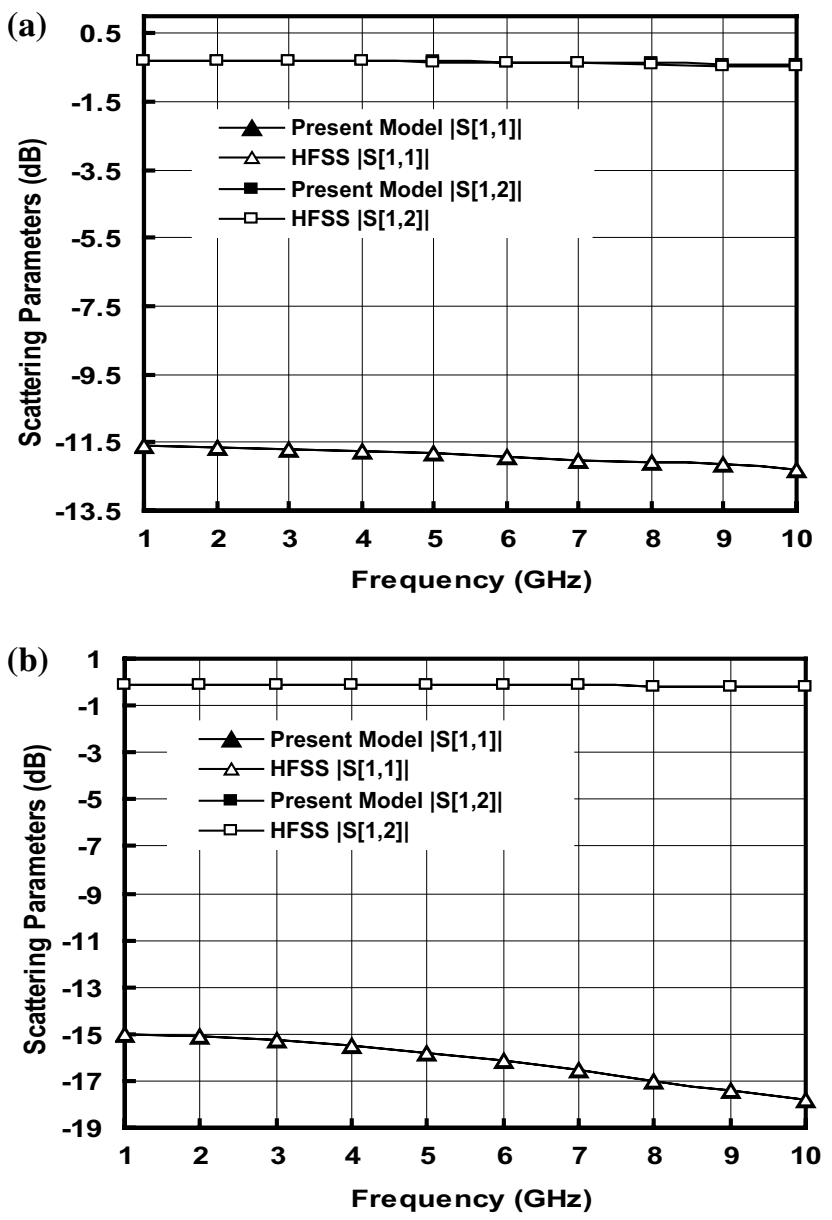

Fig. 9 Sacattering parameters of microstrip step multilayer anisotropic substrate at $\mathbf{a} \mathrm{w}_{1} / \mathrm{H}=0.3, \mathbf{b}_{1} / \mathrm{H}=2.0$

isotropic substrate [20]. The anisotropy in the substrate and even the strip conductor has an influence on the effective relative permittivity of a microstrip line. The frequency dependent effective relative permittivity of microstrip on the anisotropic substrate is presented [5]. In this section, the effect of anisotropy, strip conductor and dispersion on pulse propagation with anisotropic substrate microstrip line are illustrated. The analysis is carried by using Fourier Transform Method [21-28] and dispersion model for the equivalent isotropic substrate [5] is used in the analysis of distortion in digital square pulse and Gaussian pulse. The results of such analysis are presented below.

\subsection{Effect of anisotropy and dispersion on pulse propagation}

For this analysis, a Gaussian pulse with a full width at half maximum $(F W H M)=10 \mathrm{ps}$ and output at the end of a 

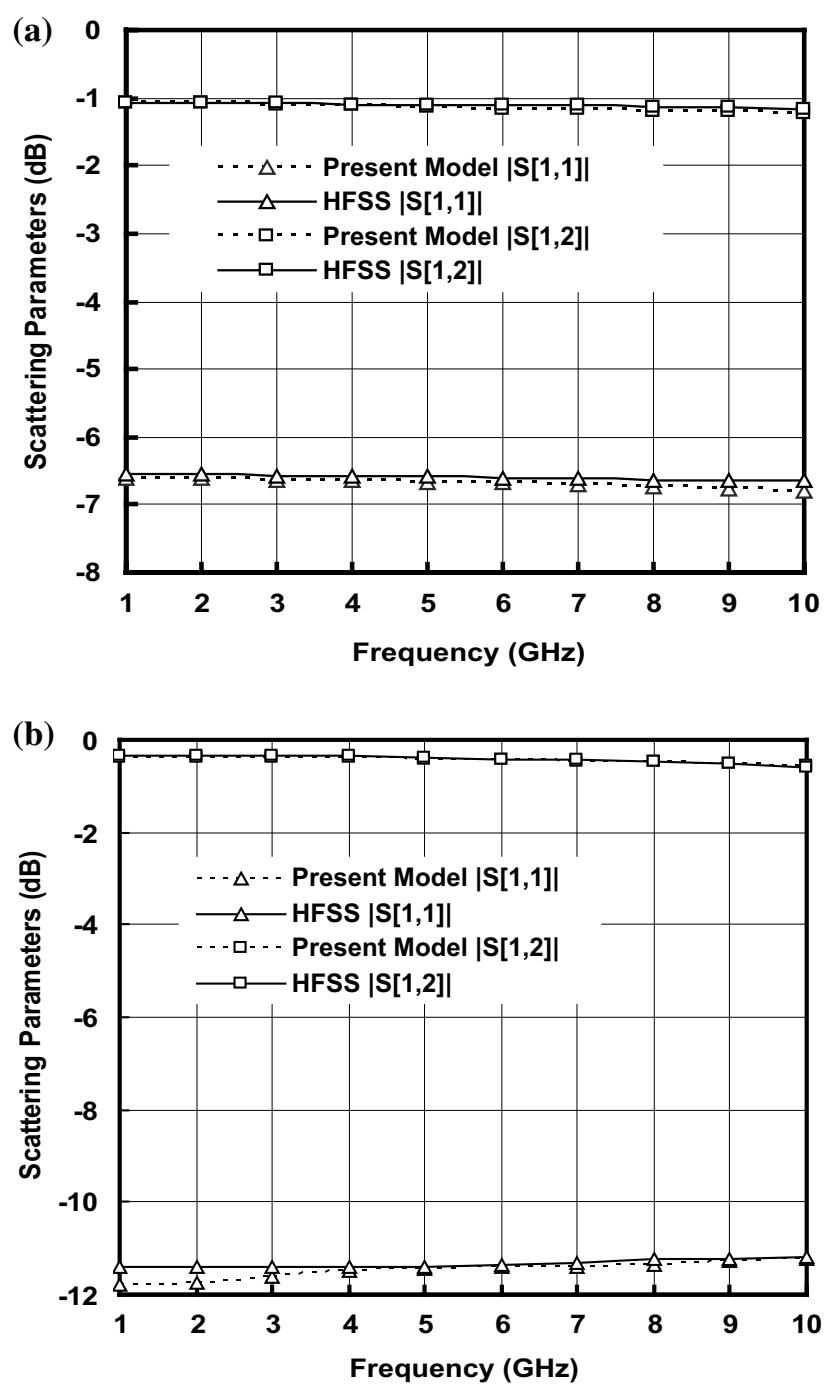

Fig. 10 Scattering parameters a $\mathrm{w}_{1} / \mathrm{H}=0.1$, a Suspended anisotropic substrate, $\mathbf{b} \mathrm{w}_{1} / \mathrm{H}=0.3$, Suspended anisotropic substrate

microstrip line on an anisotropic sapphire substrate having permittivity $\varepsilon_{\mathrm{ry}}=11.6, \varepsilon_{\mathrm{rx}}=9.4$. The line has of $\mathrm{w} / \mathrm{h}=0.05$ and length $L=0.354$ inch. The pulse position on the time scale is influenced by the anisotropy and it is determined by the effective relative permittivity as shown in Fig. 11 a.

The pulse position on the anisotropic substrate microstrip is in between the pulse position of two pulses corresponding to two extreme values of isotropic relative permittivity. Therefore, the anisotropy also widens the pulse width and increases pulse distortion to some extent [22].
Moreover, the propagation of identical Gaussian pulse on the same anisotropic substrate microstrip line with different values of $\mathrm{w} / \mathrm{h}=0.1,1.0,10$ as shown in Fig. $11 \mathrm{~b}$ and the propagation of pulse at $\mathrm{w} / \mathrm{h}=10$ are delayed modes. However, the distortion is more on the narrow width $(\mathrm{w} / \mathrm{h}=0.1)$ line. Again the position of pulses is determined by the value of effective relative permittivity.

In addition, the relative positions of Gaussian pulses of $10 \mathrm{ps}$ pulse width propagation over the microstrip line with static/dynamic effective relative permittivity for isotropic and anisotropic substrates are presented as shown in Figs. 11,12 and 13 for different $\mathrm{w} / \mathrm{h}=0.1,1.0$ and 10 respectively. It is also observed that the anisotropy influences the time of arrival of pulse at the output of the microstrip line and some extent dispersion is too influenced by the anisotropy. Figure 13b shows that the effect of distortion is less on 100 ps Gaussian pulse at a narrow width of the microstrip line.

\subsection{Effect of misalignment angle of anisotropy on propagation of various pulses}

The completely aligned $\left(\theta=0^{\circ}\right)$ anisotropic sapphire substrate has $\varepsilon_{\mathrm{ry}}=11.6, \varepsilon_{\mathrm{rx}}=9.4$ relative permittivity components. However if misalignment increase from $\theta=0^{\circ}$ to $60^{\circ}$, the effective relative permittivity is reduced.

It changes the position of 10 ps Gaussian pulse on time scale; as shown in Fig. 14a for microstrip with $w / h=10$ without dispersion. Undistorted Gaussian pulses amplitude increase slightly with increase the misalignment angle between crystal and physical axis up to $45^{\circ}$ and then decrease slightly with increase the misalignment angle between crystal and physical axis. But there is time shift in pulses with a change in misalignment angle between crystal and physical axis for a wider width. For $w / h=10$, Fig. 14b studies the effect of misalignment angle on the pulse propagation with dispersion. The effect is visible for large misalignment.

However, if the misalignment is less than $15^{\circ}$, its effect is small. A large misalignment angle also increases the pulse distortion to some extent. But there is time shift in pulses with a change in misalignment angle between crystal and physical axis for wider width microstrip. Figure 15 shows that the misalignment angle has practically no influence on the pulse on the narrow width, $\mathrm{w} / \mathrm{h}=0.1 \mathrm{microstrip}$ line.

Figure $16 a, b$ show effect of the misaligned optic axis on output $10 \mathrm{ps}$ square pulse traveling on non-dispersive and dispersive anisotropic substrate microstrip with $\left(\varepsilon_{\mathrm{ry}}=11.6\right.$, $\left.\varepsilon_{\mathrm{rx}}=9.4\right)$ and $\mathrm{w} / \mathrm{h}=10$. We note that with an increase in 
Fig. 11 a Propagation of $10 \mathrm{ps}$ pulse width on anisotropic substrate microstrip line with constant $\mathrm{w} / \mathrm{h}=0.05, \mathbf{b}$ $\mathrm{w} / \mathrm{h}=0.1,1.0,10.0$ misalignment angle $\theta$, relative effective permittivity decreases and pulse arrives earlier than the pulse on the aligned optic axis. Thus, the position of the pulse on the time- axis is more sensitive to the misalignment angle. The dispersion causes an increase in rise-time and also overshoots. These are comparatively less for the misaligned optic axis.
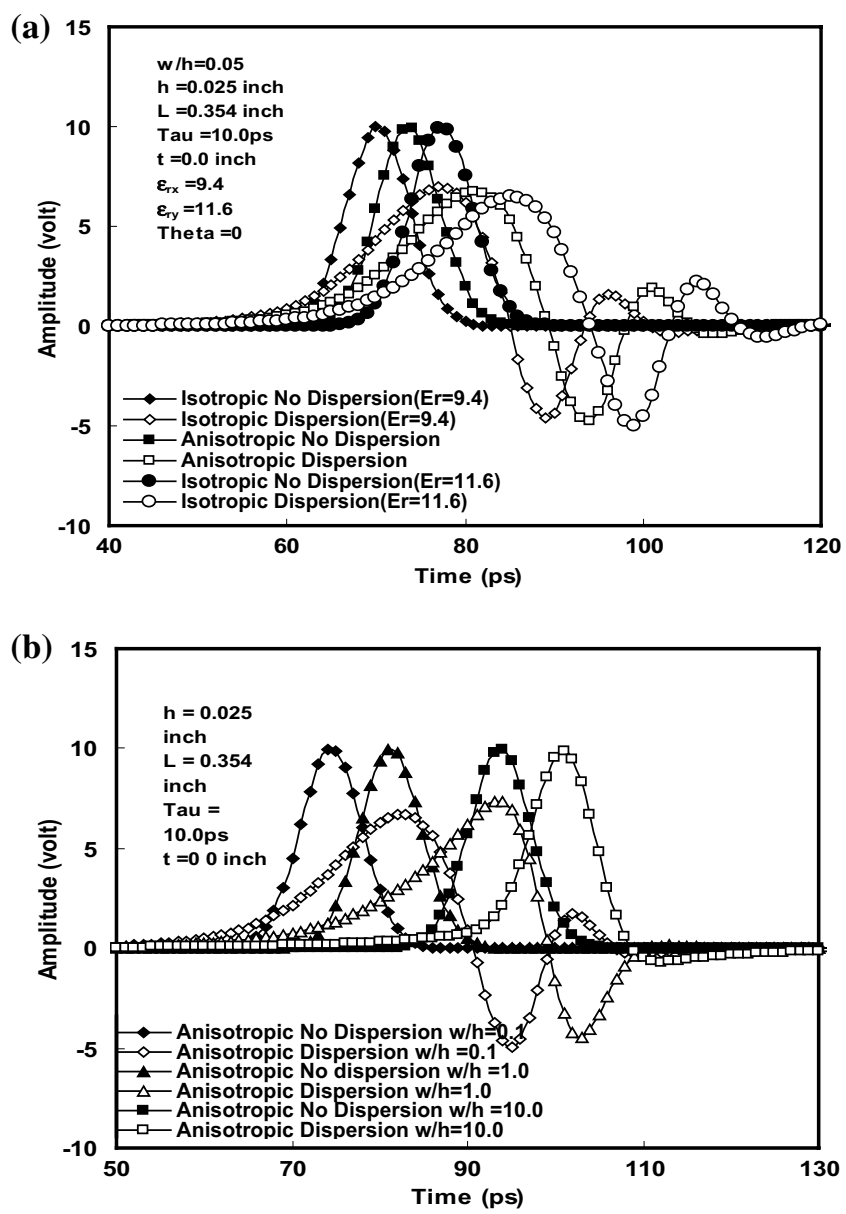

Figure $17 \mathrm{a}, \mathrm{b}$ examine 10 ps square pulse traveling on non-dispersive and dispersive anisotropic substrate microstrip with $\left(\varepsilon_{\mathrm{ry}}=11.6, \varepsilon_{\mathrm{rx}}=9.4\right)$ and $\mathrm{w} / \mathrm{h}=10$. Figure $17 \mathrm{a}$ shows that the pulses are not shifting, with changes $t / h$ with time for wider width $w / h=10$ microstrip line. However, Fig. 17b shows that the pulses are severely distorted due to the dispersion at the output. 

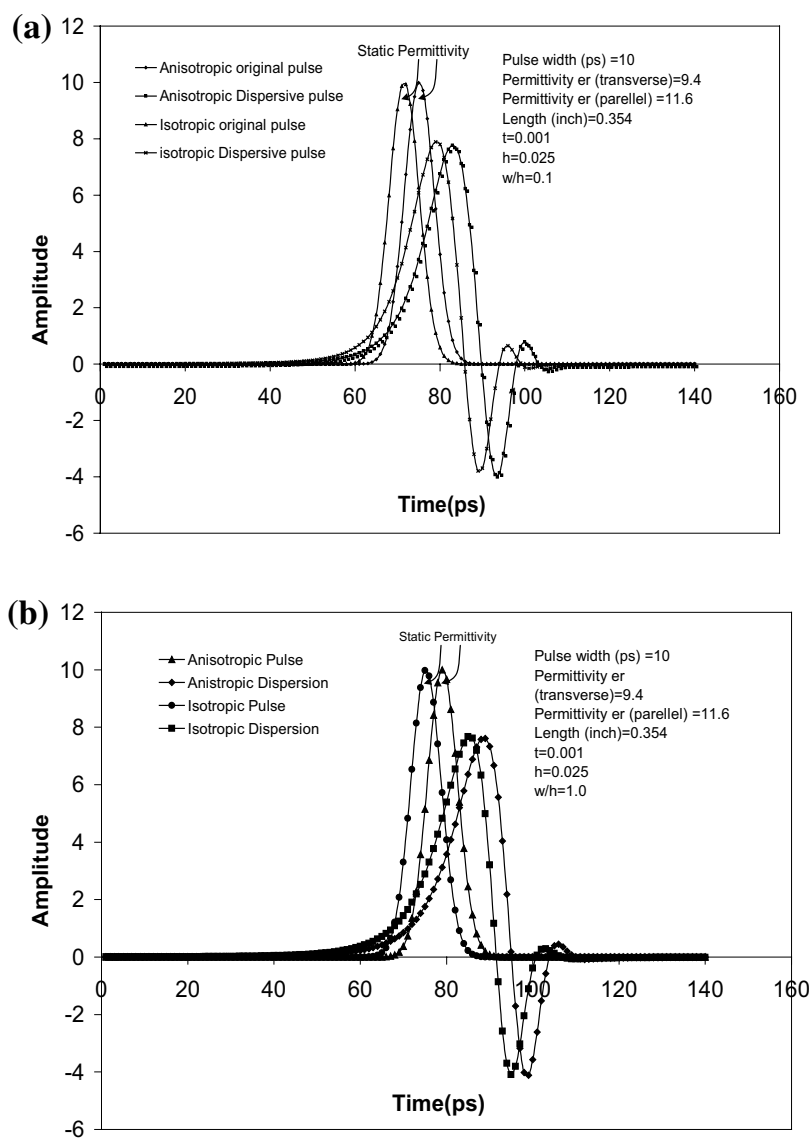

Fig. 12 Propagation of 10 ps pulse width on anisotropic substrate microstrip line with $\mathbf{a} w / \mathrm{h}=0.1, \mathbf{b} w / \mathrm{h}=1.0$

\subsection{Effect of strip conductor thickness $(t)$ on pulse propagation}

The strip conductor thickness reduces the value of the effective relative permittivity of a microstrip line. Figure 18 demonstrate shifting of 10 ps Gaussian pulse on $\mathrm{w} / \mathrm{h}=0.1$ microstrip line for strip conductor in the range $(0.0 \leq \mathrm{t} / \mathrm{h} \leq 0.2)$.

The dispersion is ignored for clarity. Figure $19 a$, b shows the effect of strip conductor thickness for 10 ps Gaussian pulse on non-dispersive and dispersive microstrip line having $\mathrm{w} / \mathrm{h}=1.0$ and 10 respectively. On dispersive microstrip effect of conductor thickness on the pulse, shifting is
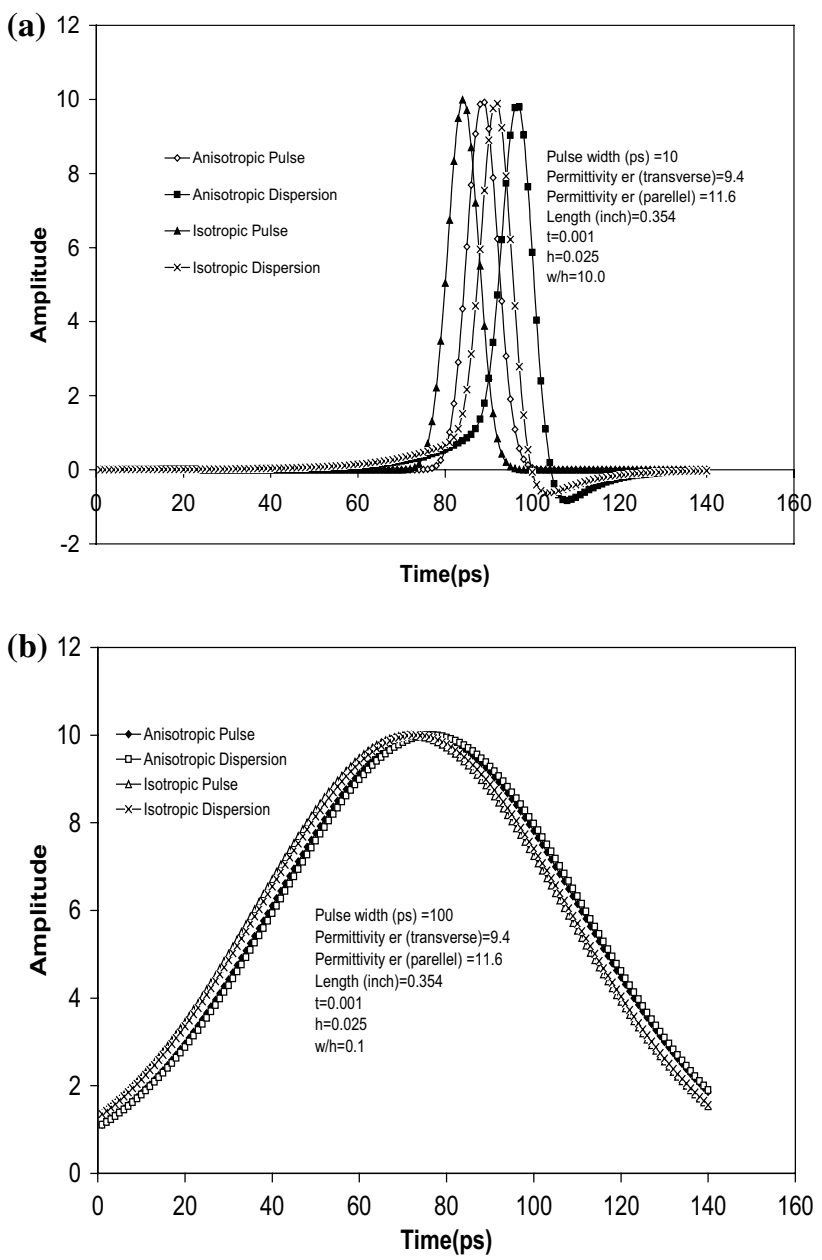

Fig. 13 Pulse propagation on anisotropic substrate at $\mathbf{a} w / \mathrm{h}=10$ with pulse width $=10 \mathrm{ps}, \mathbf{b} \mathrm{w} / \mathrm{h}=0.1$ with pulse width $=100 \mathrm{ps}$

reduced. The reduction is more for wider microstrip. The pulse distortion is also less for the wider microstrip line. Table 1 represents the effect of misalignments of an axis of anisotropy at zero conductor thickness and Table 2 shows the effects of conductor thickness at the aligned axis of anisotropy.

Finally, we can state that for the correct positioning of pulses propagating on microstrip line attention must be paid to the strip conductor thickness, anisotropy in the substrate, proper alignment of optic axis $\theta \leq 15^{\circ}$ is needed 

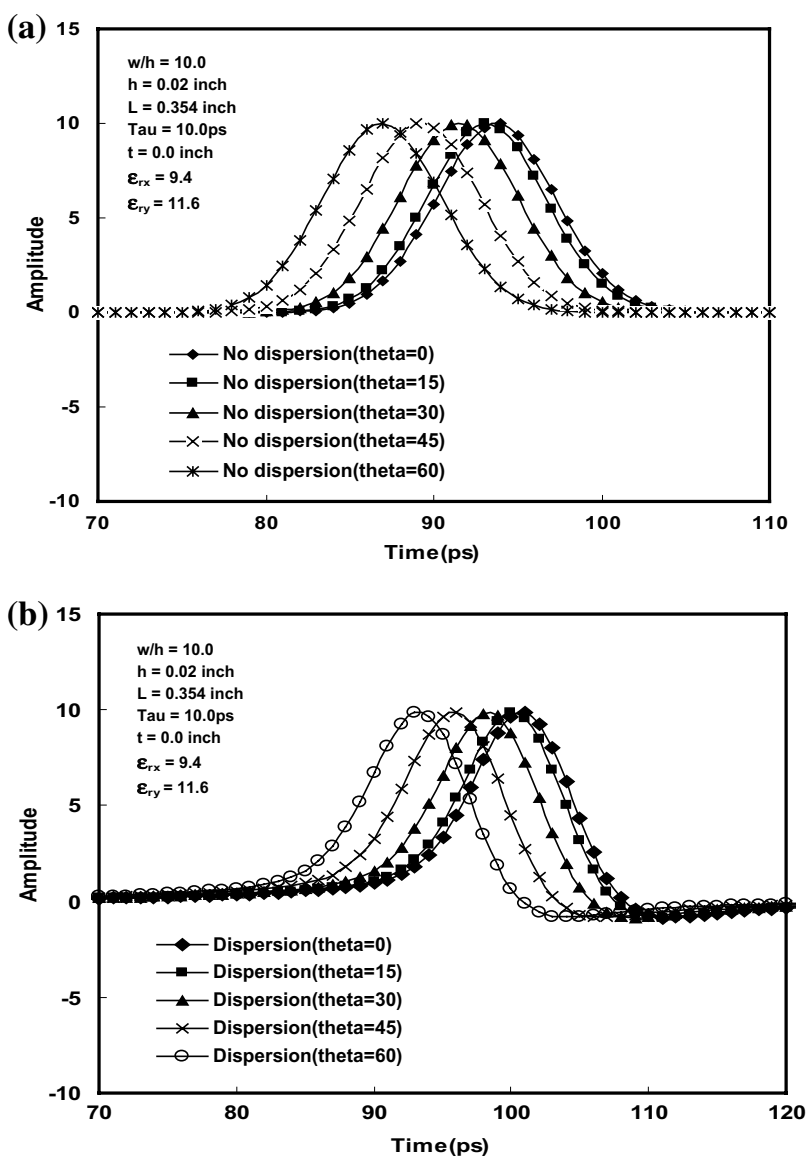

Fig. 14 Effect of misalignment of the axis on 10 ps Gaussian pulse at $\mathrm{w} / \mathrm{h}=10$ a without dispersion, $\mathbf{b}$ with dispersion

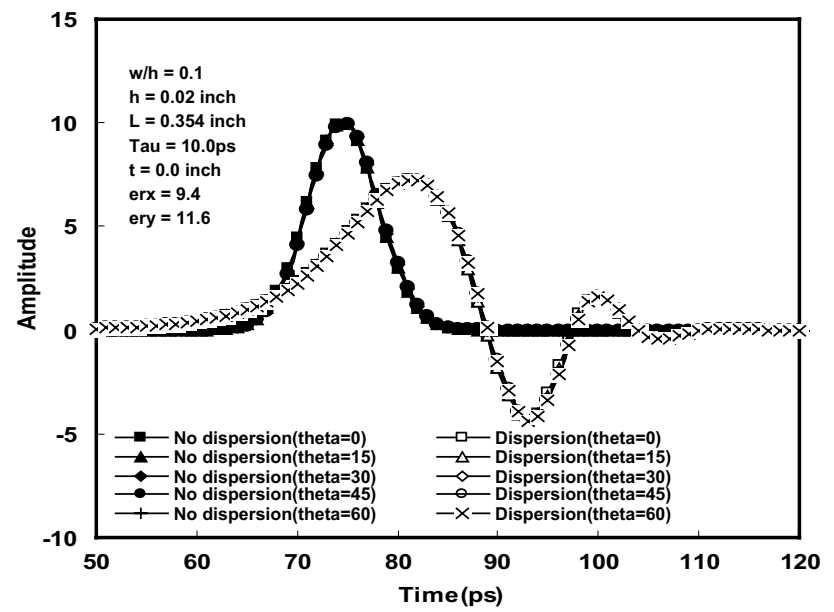

Fig. 15 Pulse propagation (pulse width $=10 \mathrm{ps)}$ on microstrip anisotropic substrate at $\mathrm{w} / \mathrm{h}=0.1$
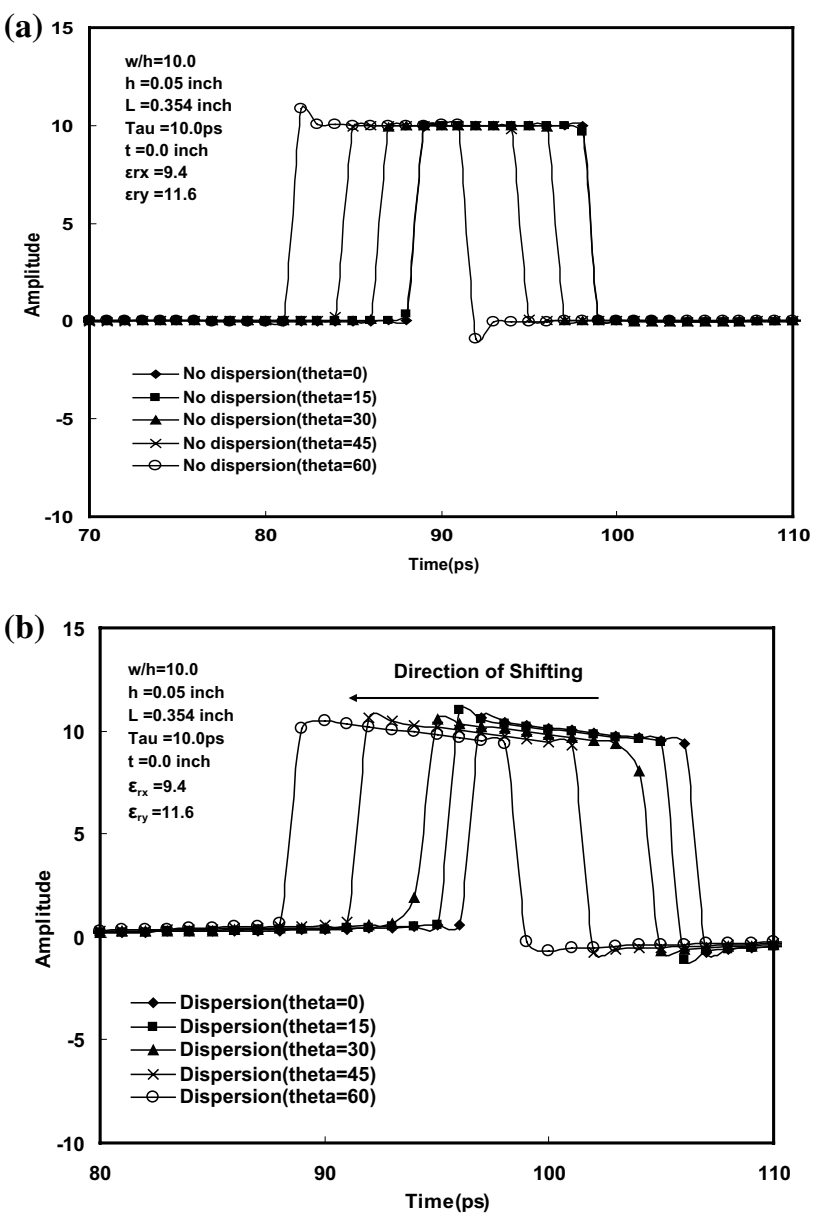

Fig. 16 Effect of misaligned of the axis on 10 ps square pulse on the anisotropic substrate at $\mathrm{w} / \mathrm{h}=10$ a without dispersion, $\mathbf{b}$ with dispersion

in order to avoid its effect on the time of arrival of the signal at the output of line.

\section{Conclusion}

Shunt capacitance and series inductance have been modeled and analyzed at the junction of microstrip step discontinuity on the various iso/anisotropic multilayer substrates. Results of all Models have made good agreement with EM-simulation results as shown in Table 3. Analysis of transient pulses on modeled microstrip transmission line has been found suitable for VLSI interconnect technology on multilayer iso/anisotropic substrate. Hence, designed modeling concept is fostering of contemporary planar microwave filters and impedance matching networks and better than the existing models for the same. 

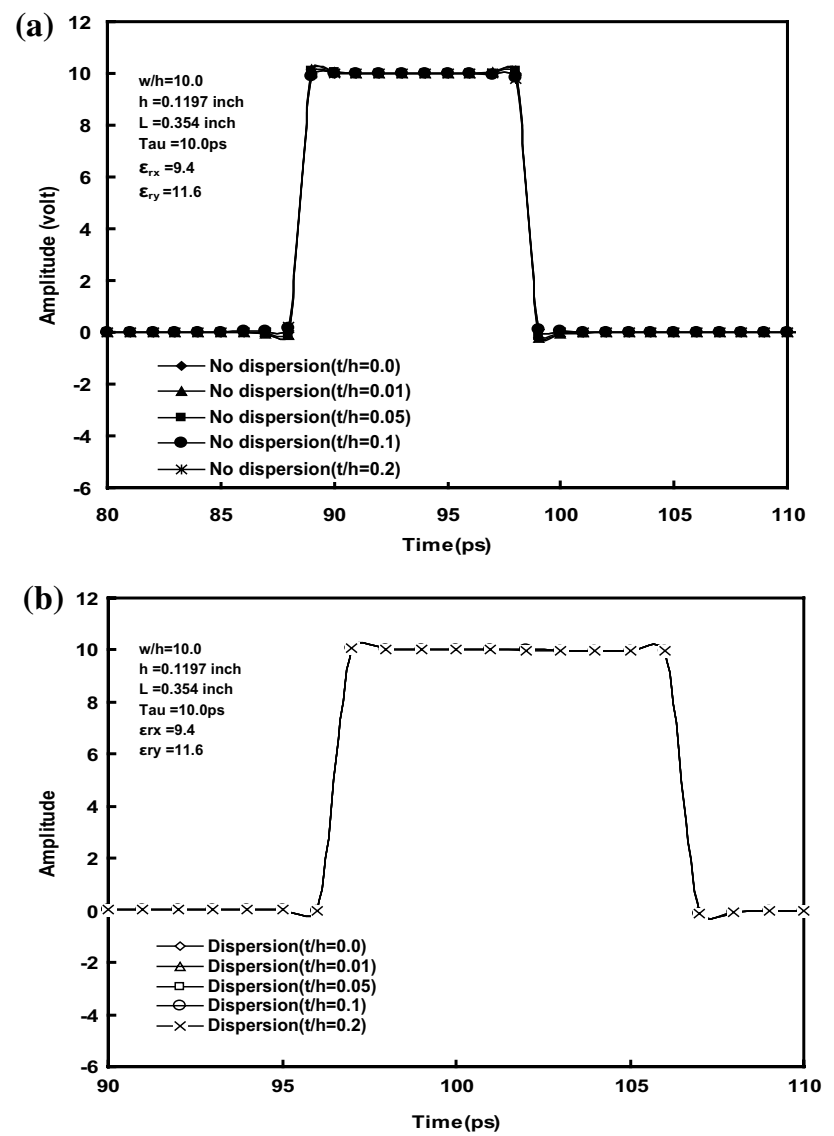

Fig. 17 Effect of $t / h$ on 10 ps Square pulse on anisotropic substrate microstrip at $\mathrm{w} / \mathrm{h}=10 \mathbf{a}$ without dispersion, $\mathbf{b}$ with dispersion

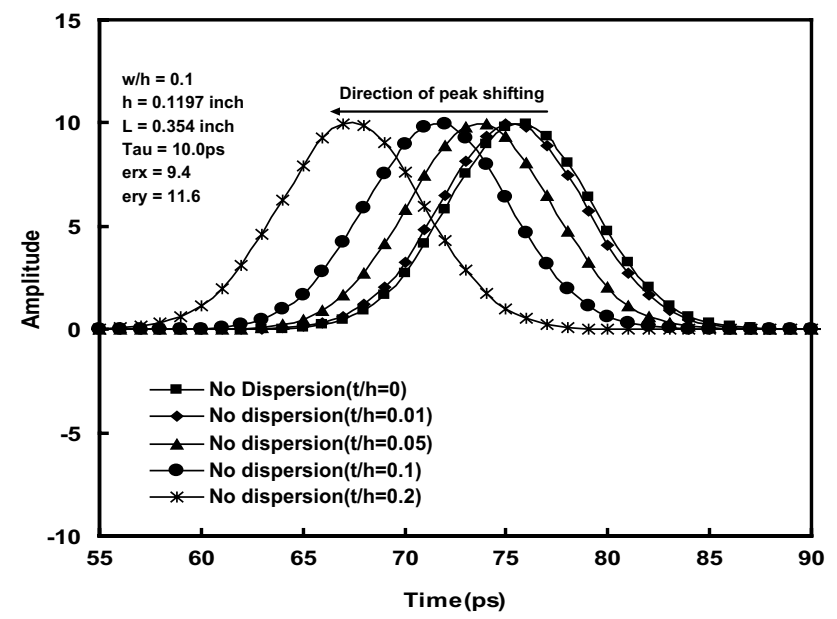

Fig. 18 The decrease in arrival time of 10 ps Gaussian pulse on $\mathrm{w} / \mathrm{h}=0.1$ microstrip line width
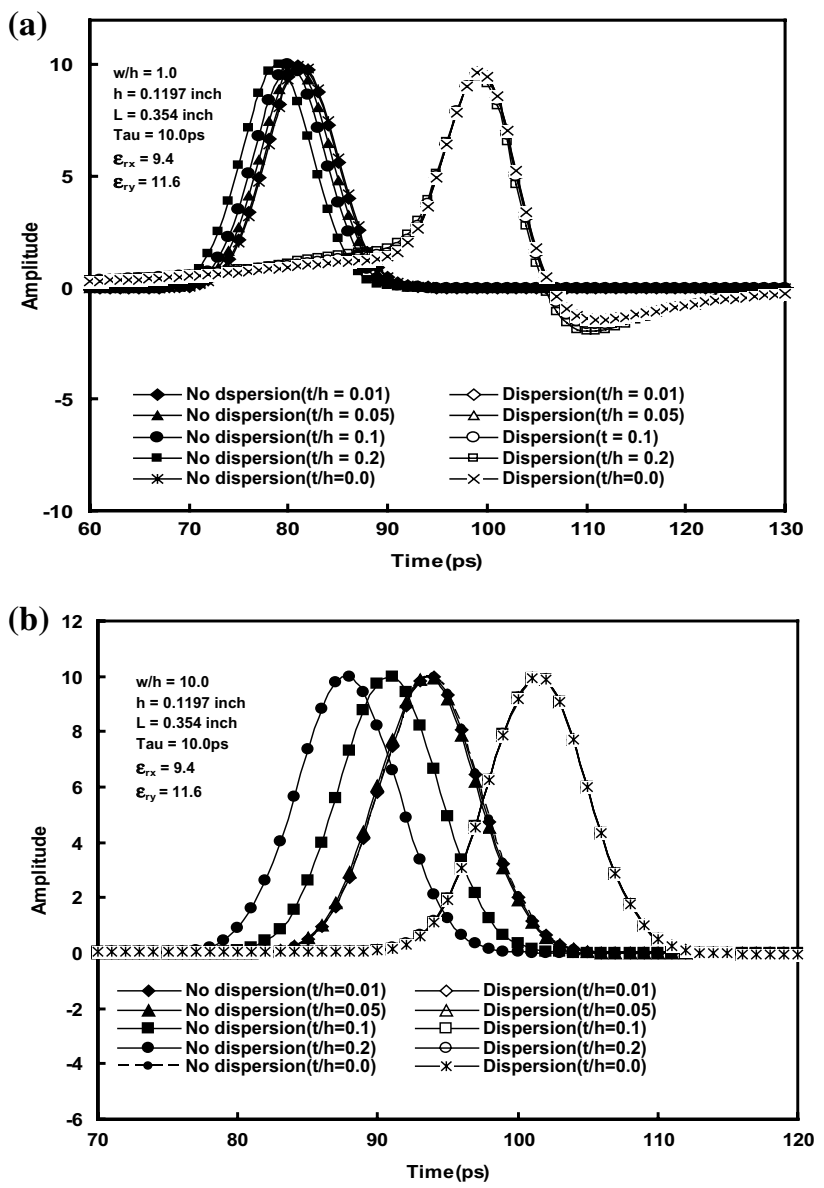

Fig. 19 Decrease in arrival time of 10 ps Gaussian pulse a on $\mathrm{w} / \mathrm{h}=1.0, \mathrm{~b}$ pulse on $\mathrm{w} / \mathrm{h}=10$

Table $1 \mathrm{~W} / \mathrm{H}=10.0, \mathrm{H}=0.05 \quad \mathrm{INCH}, \mathrm{L}=0.354 \mathrm{INCH}, \mathrm{T}=10.0 \mathrm{PS}$, $\mathrm{t}=0.0 \mathrm{INCH}, \mathrm{E}_{\mathrm{RX}}=9.4, \mathrm{E}_{\mathrm{RY}}=11.6$

\begin{tabular}{llll}
\hline$\theta^{\circ}$ & Rise time $(\mathrm{ps})$ & Delay time $(\mathrm{ps})$ & Overshoot $(\%)$ \\
\hline 0 & 0.20 & 1.50 & 2.0 \\
15 & 0.25 & 0.50 & 2.5 \\
30 & 0.20 & 1.50 & 2.5 \\
45 & 0.20 & 1.25 & 2.5 \\
60 & 0.20 & 1.50 & 11.0 \\
\hline
\end{tabular}

Table $2 \mathrm{~W} / \mathrm{H}=10.0, \mathrm{H}=0.05 \mathrm{INCH}, \mathrm{L}=0.354 \mathrm{INCH}, \mathrm{T}=10 \mathrm{ps}, \theta=0^{\circ}$, $\mathrm{E}_{\mathrm{RX}}=9.4, \mathrm{E}_{\mathrm{RY}}=11.6$

\begin{tabular}{llll}
\hline $\mathrm{t} / \mathrm{h}$ & Rise time $(\mathrm{ps})$ & Delay time $(\mathrm{ps})$ & Overshoot $(\%)$ \\
\hline 0.0 & 0.55 & 1.50 & 6.0 \\
0.01 & 0.55 & 1.50 & 6.5 \\
0.05 & 0.55 & 1.50 & 7.0 \\
0.10 & 0.55 & 1.50 & 7.5 \\
0.20 & 0.55 & 1.50 & 8.0 \\
\hline
\end{tabular}


Table 3 Comparison of proposed models with referenced results on single layer/multilayer isotropic/anisotropic substrates

\begin{tabular}{lllll}
\hline S. no. Shunt capacitance & & Series inductance & References \\
\cline { 2 - 3 } & Isotropic Anisotropic & Isotropic Anisotropic & \\
\hline
\end{tabular}

Single-layer substrate

\begin{tabular}{|c|c|c|c|c|c|}
\hline 1. & $13.53 \%$ & - & $5.3 \%$ & - & {$[5]$} \\
\hline 2. & $5.7 \%$ & - & $5.5 \%$ & - & [8] \\
\hline 3. & $5.0 \%$ & - & $5.0 \%$ & - & [29] \\
\hline 4. & $5.3 \%$ & $4.6 \%$ & $4.7 \%$ & $4.1 \%$ & {$[30]$} \\
\hline 5. & $7.0 \%$ & $5.0 \%$ & $5.2 \%$ & $4.5 \%$ & [31] \\
\hline 6. & $4.5 \%$ & $3.2 \%$ & $4.9 \%$ & $3.0 \%$ & {$\left[\mathrm{P}^{\mathrm{a}}\right]$} \\
\hline \multicolumn{6}{|c|}{ Multi-layer substrate } \\
\hline 1. & $5.0 \%$ & - & $2.9 \%$ & - & {$[5]$} \\
\hline 2. & - & - & - & - & {$[8]$} \\
\hline 3. & - & - & - & - & [29] \\
\hline 4. & $4.3 \%$ & $3.4 \%$ & $4.6 \%$ & $3.9 \%$ & [30] \\
\hline 5. & $5.5 \%$ & $3.2 \%$ & $5.4 \%$ & $2.7 \%$ & [31] \\
\hline 6. & $3.2 \%$ & $1.6 \%$ & $4.5 \%$ & $2.6 \%$ & {$\left[\mathrm{P}^{\mathrm{a}}\right]$} \\
\hline
\end{tabular}

aproposed models

\section{Compliance with ethical standards}

Conflict of interest The authors declare that they have no conflict of interest.

\section{References}

1. Gupta KC, Garg R, Bahl IJ, Bhartia P (1996) Microstrip lines and slot lines, Chapter-7, 2nd edn. Artech House, Boston, pp 147-165

2. Pramanick $P$, Bhartia $P$ (1992) CAD models for microstrip on iso/ anisotropic substrates and their application to transient analysis. Int J Microw Millim Wave Comput-Aided Eng 2:34-39

3. Awasthi YK, Verma AK, Singh H (2009) Equivalent isotropic relative permittivity of microstrip on multilayer anisotropic substrate. Int J Electron 96(8):865-875

4. Awasthi YK, Verma AK, Singh $H$ (2009) Closed-form model of $\mathrm{W} / \mathrm{h}$ - dependent equivalent isotropic relative permittivity of microstrip on multilayer anisotropic substrate. Int J Microw Opt Technol 4(2):107-114

5. Awasthi YK, Verma AK, Singh H (2009) Circuit model of multilayer microstrip step discontinuity using SLR formulation. Int J Electromagn 29(6):483-498

6. Verma AK, Singh P, Matekovits L (2014) Strip-width and slotgap dependent equivalent isotropic substrate and dispersion characteristics of asymmetric coplanar waveguide, symmetric coplanar waveguide and micro-coplanar strip line on anisotropic substrates. IEEE Trans Microw Theory Tech 62:2232-2241

7. Kneppo I, Fabian J, Bezousek P, Hrniko P, Pavel M (1994) Microwave integrated circuit, Chapter-2. Chapman \& Hall, pp 19-27

8. Norbert HLK, Janson RH (1986) The microstrip step discontinuity: a revised description. IEEE Trans Microw Theory Tech 34(2):213-223
9. Gupta R, Maktoomi MH, Singh VV, Hashmi MS (2019) High impedance transforming dual-band balun with isolation and output ports matching. Prog Electromagn Res Lett 81:121-126

10. Saxena A, Banerjee D, Hashmi M, Ghannouchi F (2018) Design of compact dual-band matching network with single unequal susceptance cancellation stub. In: IEEE Asia-Pacific Microwave Conference (APMC), pp 300-302

11. Banerjee D, Saxena A, Hashmi MS (2018) A novel concept of virtual impedance for high-frequency tri-band impedance matching networks. IEEE Trans Circuits Syst II Express Briefs 65(9):1184-1188

12. Maktoomi MH, Banerjee D, Hashmi MS (2018) An enhanced frequency-ratio coupled-line dual-frequency Wilkinson power divider. IEEE Trans Circuits Syst II Exp Briefs 65(7):888-892

13. Hoffmann RK (1987) Handbook of microwave integrated circuits. Artech House, Norwood

14. Sonnet Professional, Sonnet Software Ltd (2009) NY 13088 USA. http://www.sonnetsoftware.com. Accessed 21 Jan 2009

15. Microwave Office (2006) Applied wave research, USA. www. appwave.com. Accessed 21 Jan 2009

16. Singh H, Verma AK (2005) Closed-form model of shunt capacitance of microstrip step discontinuity. In: IEEE Asia Pacific Microwave Conference (APMC), China, vol 3, pp 4-7

17. Awasthi YK, Singh H, Sharma M, Kumari S, Verma AK (2017) CADbased circuit model of microstrip line for $\mathrm{THz}$ interconnects technology. IET J Eng 9:512-526

18. Awasthi YK, Singh H, Kumar A, Singh P, Verma AK (2010) Accurate CAD-model analysis of multilayer microstrip line on anisotropic substrate. J Infrared Millim Terahertz Waves 31(3):259-270

19. Owens P, Aitken JE, Edwards TC (1976) Quasi-static characteristics of microstrip on an anisotropic sapphire substrate. IEEE Trans Microw Theory Tech 24(8):499-505

20. Awasthi YK, Verma AK (2008) Pulse propagation on the microstrip transmission-line using an anisotropic substrate. In: IEee international conference on recent advances in microwave theory and applications, India, pp 750-753

21. Veghte RL, Balanis CA (1986) Dispersion of transient signals in microstrip transmission lines. IEEE Trans Microw Theory Tech 34(12):1427-1436

22. Leung T, Balanis CA (1988) Attenuation distortion of transient signals in microstrip. IEEE Trans Microw Theory Tech 36(4):765-769

23. Leung T, Balanis CA (1988) Pulse dispersion distortion in open and shielded microstrip using the spectral-domain method. IEEE Trans Microw Theory Tech 36(7):1223-1226

24. Gilb JP, Balanis CA (1989) Pulse distortion on multilayer coupled microstrip lines. IEEE Trans Microw Theory Tech 37:1620-1628

25. Gilb JP, Balanis CA (1990) Transient analysis of distortion and coupling in lossy coupled microstrip. IEEE Trans Microw Theory Tech 38:1894-1899

26. Lina Z, Lina S, Qiua W, Fang Y (2018) Numerical modeling of pulse propagation through a double-negative metamaterial with adjacent absorptive and gain Lorentz dispersions: a comparison. Optik 154:10-14

27. Lu X, Stephens JC, Mastovsky I, Shapiro MA, Temkin RJ (2018) High power long pulse microwave generation from a metamaterial structure with reverse symmetry. Phys Plasmas 25(2):023102

28. Papasimakis N, Raybould T, Fedotov VA, Tsai DP, Youngs I, Zheludev NI (2018) Pulse generation scheme for flying electromagnetic doughnuts. Phys Rev B 97(20):201409

29. Garg R, Bahl IJ (1978) Microstrip discontinuities. Int J Electron 45(01):81-87 
30. Martel J, Rafael RB, Horno M (1994) Analysis of a microstrip crossover embedded in multilayered anisotropic and lossy media. IEEE Trans Microw Theory Tech 42(03):424-432

31. Drake E, Rafael RB, Horno M, Sarkar TK (2000) Effect of substrate dielectric anisotropic on the frequency behavior of microstrip circuits. IEEE Trans Microw Theory Tech 48(08):1394-1403
Publisher's Note Springer Nature remains neutral with regard to jurisdictional claims in published maps and institutional affiliations. 